\title{
Adsorption mechanism and modelling of hydrocarbon contaminants onto rice straw activated carbons
}

\author{
Mahmoud M. Abdel daiem ${ }^{1,2 *}$, Manuel Sánchez-Polo ${ }^{3}$, Ahmed S. Rashed ${ }^{4}$, Nehal Kamal ${ }^{5}$, \\ Noha Said ${ }^{1}$ \\ ${ }^{1}$ Environmental Engineering Department, Faculty of Engineering, Zagazig University, 44519, Zagazig, Egypt \\ ${ }^{2}$ Civil Engineering Department, College of Engineering, Shaqra University, Dawadmi, 11911, Ar Riyadh, Saudi Arabia \\ ${ }^{3}$ Inorganic Chemistry Department, Faculty of Science, Granada University, 18071, Granada, Spain \\ ${ }^{4}$ Physics and Engineering Mathematics, Faculty of Engineering, Zagazig University, 44519, Zagazig, Egypt \\ ${ }^{5}$ Microbiology Department, Faculty of Science, Suez University, Suez, Egypt \\ "Corresponding author: e-mail: mmabdeldaim@zu.edu.eg
}

\begin{abstract}
The adsorption of Diphenolic acid (DPA), 2,4-Dichlorophenoxyacetic acid (2,4-D), and 2-methyl-4-chlorophenoxyacetic acid (MCPA) were examined in aqueous solution using activated carbon rice straw. The rice straw was activated by using two reagents, zinc chloride and phosphoric acid and named as RSZ, RSP, respectively. The results showed that both carbons have a relatively high adsorption capacity. Concerning the adsorption kinetic, the second-order model has better fit than the first model to experimental data. The adsorption yield of both carbons increased in the order: DPA < 2,4-D < MCPA. The pore volume diffusion model satisfactorily fitted the experiment on both carbons. Furthermore, solution $\mathrm{pH}$ has a high influence on the adsorption capacity for both carbons. The adsorption mechanism of selected pollutants onto carbon samples has been controlled by dispersion interaction $\pi-\pi$ electrons and electrostatic interaction, moreover, the contribution of pore volume diffusion is the controlling mechanism of the overall rate of adsorption.
\end{abstract}

Keywords: Activated carbon, rice straw, adsorption mechanism, adsorption modeling, pore volume surface diffusion.

\section{INTRODUCTION}

Contamination of natural waters is a problem worldwide, which can have grave consequences on the health of both humans and animals ${ }^{1}$. Large amounts and various organic hydrocarbons (e.g. pesticides, plasticizers) contaminate natural water sources and other natural resources. This is mostly due to the worsening unsustainable anthropogenic activities (industrial, urban, agricultural, farming, etc. $)^{2}$.

The novel effects of herbicides at significant concentrations in the environment was reported recently by Orton et al. ${ }^{3}$. Due to being low cost and of good selectivity ${ }^{4}, 2,4$-dichlorophenoxyacetic acid (2,4-D) is a broadly used herbicide ${ }^{5}$. Moreover, both in cultivated and non-cultivated application, 4-chloro-2-methylphenoxiacetic acid (MCPA) is frequently used to control a broad variety of broadleaf weeds ${ }^{6}$. Both compounds (2,4-D and MCPA) proved relatively pervasive in global drinking water sources ${ }^{7}$.

In the recent decade, it was observed that in order to synthesize new polyesters and polycarbonates, Diphenolic acid (DPA) was generally preferred over Bisphenol A $(\mathrm{BPA})^{8,9}$. This is mainly due to DPA being more commercially available and much cheaper than BPA. As a result, DPA became the more abundant environmental pollutant than BPA. DPA is known to cause; a) severe endocrine system damage, b) carcinogenesis, c) liver damage and d) obesity-promoting ${ }^{10}$. DPA was also detected in various water systems ${ }^{11}$.

Mailler et al. ${ }^{12}$ examined the adsorption process of hydrocarbons on activated carbon and found a strong correlation between the absorption efficiency of activated carbons and their specific surface (BET). Ocampo-Pérez et al. ${ }^{13}$ examined the adsorption rates of 2,4-D, DPA and MCPA and other pollutants on two commercially activated carbons. They found that both diffusional and kinetic models successfully fit the experimental adsorption rate data. Abdel daiem et al. ${ }^{14}$ use of gamma radiation to oxidize DPA in aqueous solution proved to be an excellent option in removing DPA from aqueous solutions. The DPA degradation increases at higher irradiation doses but decreased in the presence of different anions in the aqueous solution. Rivera-Utrilla et al. ${ }^{15}$ studied the 2,4-D photodegradation by using $\mathrm{UV} / \mathrm{TiO}_{2}$ in the presence of different original and oxidized activated carbons. The results showed that the presence of ozonated activated carbons with a high carboxyl groups contents enhanced 2,4-D photodegradation by the $\mathrm{UV} / \mathrm{TiO}_{2}$ system, mineralized $40 \%$ of total organic carbon and reduced the toxicity of the degradation by-products. Tchaikovskaya et al. ${ }^{16}$ investigated the photodegradation of MCPA by UV radiation using $\mathrm{KrCl}$ and $\mathrm{XeBr}$ excilamps. They showed that by using excilamps caused the effective phototransformation of MCPA. Coupling of photo and bioprocess allow the removal of initial pollutant and photo products from water.

Activated carbon has been proven to be an effective adsorbent in aqueous media due to their highly developed porosity and surface area ${ }^{17}$. In recent years, the considerable attention of scientists has been devoted to preparing activated carbon materials from different agriculture biomass residues to help environmental protection $^{18-20}$.

Preparation of activated carbon from lignocellulose wastes is an effective method of solid waste recycle from the environmental point of view. Rice straw is considered to be one of the most important agriculture residues due to its high production worldwide, around 731 million tons/year ${ }^{21}$. Daifullah et al. ${ }^{18}$ investigated the preparation of activated carbon by one-step steam pyrolysis of rice straw at $550,650,750^{\circ} \mathrm{C}$ and modified 
it by liquid-phase oxidation using $\mathrm{HNO}_{3}, \mathrm{H}_{2} \mathrm{O}_{2}$, and $\mathrm{KMnO}_{4}$. They reported that the surface area of activated carbon samples ranged from 63 to $113 \mathrm{~m}^{2} / \mathrm{g}$. Furthermore, Ahmedna et al. ${ }^{22}$ prepared activated carbons from rice straw by physical activation at $750^{\circ} \mathrm{C}$ and found their surface area less than $200 \mathrm{~m}^{2} / \mathrm{g}$.

From this background, the main objectives of this study is thus established as: i) preparing activated carbon with optimally developed porosity and surface area from rice straw using zinc chloride and phosphoric acid, ii) studying the adsorption kinetics of 2,4-D, MCPA and DPA on prepared activated carbons by using diffusional and kinetic models, iii) analysing the influence of solution $\mathrm{pH}$ and ionic strength on adsorption yield to investigate the adsorption mechanism of selected pollutants in both activated carbons, iv) to study a selected pollutant adsorption process in a dynamic regime.

\section{MATERIALS AND PREPARATION METHODOLOGY}

\section{Reagents}

The chemical reagents utilized in this study are; 2,4D, MCPA, DPA, zinc chloride, phosphoric acid, sodium chloride, sodium hydroxide and hydrochloric acid. All high-purity analytical grade reagents were supplied by Sigma-Aldrich. All the ultrapure water used were obtained from Milli-Q ${ }^{\circledR}$ equipment Millipore.

The concentrations of 2,4-D, DPA and MCPA were determined using UV-visible spectrophotometer (Genesys 5) at a wavelength of 284, 279 and $276 \mathrm{~nm}$, respectively. The physic-chemical prosperities of these pollutants are presented in Table 1

\section{Preparation of activated carbons}

Two activated carbons were prepared from rice straw. They were obtained from Sevilla, Spain. The physical properties of rice straw used in this work showed that: ash content is $10.63 \%$, volatile matter is $89.90 \%$, carbon is $42.82 \%$, hydrogen is $7.18 \%$ and nitrogen is $0.78 \%{ }^{23}$. The rice straw sample was shredded into a particle size of less than $4 \mathrm{~mm}$ then washed with distilled water to remove any impurities and dried at $110^{\circ} \mathrm{C}$, overnight. The dried samples were mixed with $\mathrm{ZnCl}_{2}$ or $\mathrm{H}_{3} \mathrm{PO}_{4}$ with impregnation ration (1:1) by weight (rice straw: activation agent) for two days at $60^{\circ} \mathrm{C}$, and were designated as samples RSZ and RSP, respectively. The two samples were pyrolyzed under $\mathrm{N}_{2}$ (flowrate $=300 \mathrm{~cm}^{3} /$ $\min )$ at $300^{\circ} \mathrm{C}$ for $2 \mathrm{~h}$ and then at $800^{\circ} \mathrm{C}$ for $1 \mathrm{~h}$ at a heating rate of $10^{\circ} \mathrm{C} / \mathrm{min}$. The activated carbons obtained were then washed with distilled water to remove the phosphorous or zinc compounds until neutralization. The washed samples were then dried at $105^{\circ} \mathrm{C}$ for $24 \mathrm{~h}$, finally obtaining the desired powder activated carbon. The activated carbon samples produced were chemically and texturally characterized. The methods and techniques used in characterization are detailed $\mathrm{in}^{24-26}$.

\section{Adsorption kinetics and diffusion}

The adsorption kinetics of the selected pollutants on the prepared activated carbons were observed by adding $100 \mathrm{mg}$ of activated carbon sample in a $200 \mathrm{~mL}$ Erlenmeyer flasks containing $100 \mathrm{mg} / \mathrm{L}$ of selected pollutants. The flasks were then stored in a thermostatic mechanical shaker batch operating at a constant agitation speed of $135 \mathrm{rpm}$. The temperature was set at $298^{\circ} \mathrm{K}$ and the solution $\mathrm{pH}$ maintained at 3.20 (without any addition). The kinetic experiment resulted in a period to equilibrium of 7 days for DPA and 2,4-D and a period to

Table 1. Physical and chemical properties of the selected pollutants

\begin{tabular}{|c|c|c|c|c|c|c|c|c|c|c|}
\hline Pollutant & $\begin{array}{c}\text { Molecular } \\
\text { Weight } \\
\text { [g/mol] }\end{array}$ & $\begin{array}{c}\text { Molecular Size } \\
{[\mathrm{nm}]}\end{array}$ & $\begin{array}{c}\text { Molecular } \\
\text { formula }\end{array}$ & \begin{tabular}{|c|} 
Maximal \\
projection \\
area \\
{$\left[\mathrm{nm}^{2}\right]$} \\
\end{tabular} & $\begin{array}{c}V_{A^{a}}^{\text {a) }} \\
{\left[\mathrm{cm}^{3} / \mathrm{mol}\right]}\end{array}$ & $\begin{array}{c}\text { Solubility } \\
\text { in water } \\
\text { [g/L] }\end{array}$ & $\log K_{\text {ow }}{ }^{b}$ & $\mathrm{pK}_{\mathrm{a}_{1}}{ }^{{ }^{\prime}}$ & $\mathrm{pK}_{\left.\mathrm{a}_{2}{ }{ }^{\mathrm{d}}\right)}$ & $\left.\mathrm{pK}_{\mathrm{a}_{3}}{ }{ }\right)$ \\
\hline DPA & 286.33 & $1.27 \times 1.23 \times 0.96$ & & 0.77 & 315 & 0.40 & 3.58 & 4.66 & 9.70 & 10.45 \\
\hline 2,4-D & 221.00 & $1.29 \times 0.73 \times 0.42$ & & 0.62 & 182 & 2.16 & 2.69 & 2.98 & - & - \\
\hline MCPA & 200.62 & $1.24 \times 0.84 \times 0.42$ & & 0.62 & 185 & 1.38 & 2.22 & 3.14 & - & - \\
\hline
\end{tabular}

a) Liquid molar volume at the standard boiling point.

b) Log octanol-water partition coefficient.

c, d, e) $\mathrm{pK}_{\mathrm{a}}$ corresponding to the successive deprotonations. 
equilibrium of 8 days for MCPA. The adsorption kinetic models commonly used are represented as the first- and second-order kinetic equations shown below:

$q=q_{\text {pred, } 1}\left(1-e^{-k_{1} t}\right)$

$\mathrm{q}=\frac{\mathrm{q}_{\text {pred, } 2 \mathrm{k}_{2} \mathrm{t}}}{1+\mathrm{q}_{\text {pred, }, 2} \mathrm{k}_{2} \mathrm{t}}$

Moreover, the diffusion model is derived with the following assumptions: i) intraparticle diffusion (pore volume diffusion and surface diffusion), ii) the rate of adsorption on an active site is instantaneous, and iii) powder activated carbon particles are spherical. Choong et al. ${ }^{27}$ and Leyva-Ramos and Geankoplis, ${ }^{28}$ have described the model equations and its initial and boundary conditions by the following equations:

$\mathrm{V} \frac{\mathrm{dC}_{\mathrm{A}}}{\mathrm{dt}}=-\mathrm{mSk}_{\mathrm{L}, \exp }\left(\mathrm{C}_{\mathrm{A}}-\left.\mathrm{C}_{\mathrm{Ar}}\right|_{\mathrm{r}=\mathrm{R}_{\mathrm{p}}}\right)$

$\mathrm{t}=0, \quad \mathrm{C}_{\mathrm{A}}=\mathrm{C}_{\mathrm{A} 0}$

$\varepsilon_{\mathrm{p}} \frac{\partial \mathrm{C}_{\mathrm{Ar}}}{\partial \mathrm{t}}+\rho_{\mathrm{p}} \frac{\partial \mathrm{q}}{\partial \mathrm{t}}=\frac{1}{\mathrm{r}^{2}} \frac{\partial}{\partial \mathrm{r}}\left[\mathrm{r}^{2}\left(\mathrm{D}_{\mathrm{ep}} \frac{\partial \mathrm{C}_{\mathrm{Ar}}}{\partial \mathrm{r}}+\mathrm{D}_{\mathrm{s}} \rho_{\mathrm{p}} \frac{\partial \mathrm{q}}{\partial \mathrm{r}}\right)\right]$

$\mathrm{C}_{\mathrm{Ar}}=0, \quad \mathrm{t}=0, \quad 0 \leq \mathrm{r} \leq \mathrm{R}_{\mathrm{p}}$

$\left.\frac{\partial \mathrm{C}_{\mathrm{Ar}}}{\partial \mathrm{t}}\right|_{\mathrm{r}=0}=0$

$\left.\mathrm{D}_{\mathrm{ep}} \frac{\partial \mathrm{C}_{\mathrm{Ar}}}{\partial \mathrm{r}}\right|_{\mathrm{r}=\mathrm{R}}+\mathrm{D}_{\mathrm{s}} \rho_{\mathrm{p}} \frac{\partial \mathrm{q}}{\partial \mathrm{r}}=\mathrm{k}_{\mathrm{L}, \exp }\left(\mathrm{C}_{\mathrm{A}}-\mathrm{C}_{\mathrm{Ar}} \mathrm{I}_{\mathrm{r}=\mathrm{R}_{\mathrm{p}}}\right)$

Three models examined in this study by applying the following models: (1) Pore volume surface diffusion model (PVSDM) which represented by equations (3-8), (2) Pore volume diffusion model (PVDM) by assuming $\left(\mathrm{D}_{\mathrm{ep}} \neq 0\right.$, $\mathrm{D}_{\mathrm{s}}=0$ ) and (3) Surface diffusion model (SDM) considering that $\left(\mathrm{D}_{\mathrm{ep}}=0, \mathrm{D}_{\mathrm{s}} \neq 0\right)$.

Matlab (software version 9.2) was used to numerically solve the coupled partial and ordinary differential equations of the three diffusion models. The Matlab code was based on finite difference scheme, forward time forward space (FTFS), of $2^{\text {nd }}$ order error approximation in both of time and space variables ${ }^{29}$.

\section{Adsorption Isotherm of Pollutants on Activated Carbons}

Adsorption isotherms were derived using the same method to obtain adsorption kinetics. Varying concentrations of each pollutant $(50,100,200,300,400$, and $500 \mathrm{mg} / \mathrm{L}$ ) was used. The effects of the solution $\mathrm{pH}$ was investigated initially at concentration $500 \mathrm{mg} / \mathrm{L}$ at varying solution $\mathrm{pH}$ values per flask (3 to 10 ) at $298^{\circ} \mathrm{K}$. The working $\mathrm{pH}$ was derived by introducing varying volumes of $\mathrm{HCl}(50 \mathrm{mM})$ and $\mathrm{NaOH}(50 \mathrm{mM})$ into the solution. A CRISON micropH2002 meter was used to measure the solution $\mathrm{pH}$.

The presence of electrolytes in the DPA, 2,4-D, and MCPA adsorption test solutions were analyzed at an initial concentration of $500 \mathrm{mg} / \mathrm{L}$. The concentrations of $\mathrm{NaCl}(0.0$ to $0.01 \mathrm{M})$ is then gradually increased. The ionic strengths of these derived solutions are similar to that of many types of water in nature ${ }^{\mathbf{3 0}}$. The solution $\mathrm{pH}$ is 3.20 (without any addition) at $298^{\circ} \mathrm{K}$.

\section{Adsorption process in dynamic regime}

Adsorption was studied in a dynamic regime by passing a solution of 2,4-D, DPA or MCPA (200 mg/L) through a glass column $(3.0 \mathrm{~cm}$ high and $1.0 \mathrm{~cm}$ diameter $)$ filled with approximately $1.0 \mathrm{~g}$ of activated carbon samples. A peristaltic pump was used to pass the pollutant solutions through the active carbon beds at: a) a flow rate of 2.5 $\mathrm{mL} / \mathrm{min}, \mathrm{b}$ ) $\mathrm{pH}$ of 3.20 (without any addition) and c) $298^{\circ} \mathrm{K}$. The techniques and methods used to derive the breakthrough curves are detailed in previous works ${ }^{\mathbf{3 0}, 31}$.

\section{RESULT AND DISCUSSION}

\section{Characterization of activated carbons}

The surface area of RSZ and RSP were determined by using nitrogen at $77^{\circ} \mathrm{K}$ which is considered as one of the most widely used techniques to assess textural properties of porous solids ${ }^{32}$. The textural characterization of prepared activated carbons is shown in Table 2. Both activated carbon samples used here have a bigger surface area compared to the ones used in Ahmedna et al. ${ }^{\mathbf{1 8}}$. and Daifullah et al. ${ }^{\mathbf{2 2}}$. Further, RSZ has a slightly bigger surface area $\left(771 \mathrm{~m}^{2} / \mathrm{g}\right)$ than that for RSP $\left(613 \mathrm{~m}^{2} / \mathrm{g}\right)$ due to the thermal treatment of the raw materials with $\mathrm{ZnCl}_{2}$. This enhances the reaction of the chemical compound on the matrix of the precursors, fragmenting cellulose, hemicellulose and lignin which develop the pore structure upon activation ${ }^{33}$.

The external surface area of carbon RSP $\left(126 \mathrm{~m}^{2} / \mathrm{g}\right)$ proved to be larger than that of carbon RSZ $\left(91 \mathrm{~m}^{2} / \mathrm{g}\right)$. Note that a sufficiently large collective volume of pores is available to the water being treated $\left(>0.40 \mathrm{~cm}^{3} / \mathrm{g}\right)$ for both activated carbons (Table 2). Micropore volume $\mathrm{W}_{\mathrm{o}}\left(\mathrm{N}_{2}\right)>\mathrm{W}_{\mathrm{o}}\left(\mathrm{CO}_{2}\right)$, resulting into insignificant constrictions at the micropore entrances. Hence, complete accessibility to $\mathrm{N}_{2}$ molecules at $77^{\circ} \mathrm{K}^{34} \cdot \mathrm{L}_{\mathrm{o}}\left(\mathrm{N}_{2}\right)$ for both activated carbon samples were larger than $\mathrm{L}_{\mathrm{o}}\left(\mathrm{CO}_{2}\right)$.

The chemical characteristic of the prepared activated carbons in Table 2 shows that in both carbons (RSZ and RSP) the ash content was very high -39.68 and 48.26 respectively. The element analysis of carbon RSZ shows that $\mathrm{Zn}$ is the highest component followed by $\mathrm{Si}$ and $\mathrm{Fe}$ $-14.45 \%, 7.91 \%$ and $6.83 \%$, respectively (Table 2). In RSP, $\mathrm{P}$ was the highest component followed by $\mathrm{Si}$ and $\mathrm{Fe}-37.19 \%, 8.93 \%$, and $5.77 \%$, respectively (Table 2). This explains the higher ash content in RSP than RSZ. $\mathrm{pH}$ of the point of zero charge was 5.80 and 2.70 for RSZ and RSP, respectively. This means that RSZ is slightly acidic while RSP is strongly acidic.

\section{Adsorption kinetic.}

The adsorption kinetics of DPA, 2,4-D, and MCPA on RSZ and RSP were investigated using first-order and second-order kinetic models (eq. 1 and 2). The model constant $\left(\mathrm{k}_{1}\right.$ and $\left.\mathrm{k}_{2}\right)$ were calculated by curve fitting the kinetic models into the experimental adsorption kinetic data curves. The model constants and their correlation coefficient $\left(\mathrm{R}^{2}\right)$ are given in Table 3. In general, the $\mathrm{R}^{2}$ values for the first and second-order models are higher than 0.90 . The only exceptions are: a) the $\mathrm{k}_{1}$ in the adsorption kinetics of 2,4-D onto both activated carbons and b) DPA onto RSP - i.e. between 0.85 and 0.9. Evidently, the two kinetic models fit relatively well 
with the experimental data (adsorption kinetic curve). It is significant to note that: a) the second-order kinetic model had $\mathrm{R}^{2}$ values greater than the $\mathrm{R}^{2}$ of the first-order

Table 2. Textural and chemical characteristics and element analysis of activated carbon samples

\begin{tabular}{|c|c|c|}
\hline \multirow[t]{2}{*}{ parameters } & \multicolumn{2}{|c|}{ Activated Carbon } \\
\hline & RSZ & RSP \\
\hline$S_{N_{2}}{ }^{a)}\left(m^{2} / g\right)$ & 771 & 613 \\
\hline$S_{e x t}{ }^{b}\left(m^{2} / g\right)$ & 91 & 126 \\
\hline$\left.V_{2}{ }^{c}\right)\left(\mathrm{cm}^{3} / \mathrm{g}\right)$ & 0.23 & 0.25 \\
\hline$V_{3}{ }^{d)}\left(\mathrm{cm}^{3} / \mathrm{g}\right)$ & 0.45 & 0.42 \\
\hline$V_{\mathrm{H}_{2} \mathrm{O}^{\mathrm{e}}}\left(\mathrm{cm}^{3} / \mathrm{g}\right)$ & 0.41 & 0.41 \\
\hline$W_{0}\left(N_{2}\right)^{f}\left(\mathrm{~cm}^{3} / \mathrm{g}\right)$ & 0.29 & 0.21 \\
\hline $\mathrm{W}_{\mathrm{o}}\left(\mathrm{CO}_{2}\right)^{\mathrm{g})}\left(\mathrm{cm}^{3} / \mathrm{g}\right)$ & 0.12 & 0.09 \\
\hline $\mathrm{L}_{\circ}\left(\mathrm{N}_{2}\right)^{\mathrm{h})}(\mathrm{nm})$ & 1.57 & 1.66 \\
\hline $\mathrm{L}_{\mathrm{o}}\left(\mathrm{CO}_{2}\right)^{i)}(\mathrm{nm})$ & 0.66 & 0.70 \\
\hline $\mathrm{W}_{\mathrm{o}}\left(\mathrm{N}_{2}\right) / \mathrm{W}_{\mathrm{o}}\left(\mathrm{CO}_{2}\right)$ & 2.42 & 2.33 \\
\hline Total acidic gro ups ${ }^{\mathrm{j})}(\mu \mathrm{eq} / \mathrm{g})$ & 12.35 & 13.91 \\
\hline Total basic groups ${ }^{k)}(\mu \mathrm{eq} / \mathrm{g})$ & 6.33 & 0.00 \\
\hline $\mathrm{pH}_{\mathrm{pzc}}{ }^{\prime \prime}$ & 5.80 & 2.70 \\
\hline Oxygen $^{\mathrm{m})}(\% \mathrm{wt})$ & 43.29 & 55.91 \\
\hline Ashes $^{n)}(\%)$ & 39.68 & 48.26 \\
\hline Si (\%) & 7.91 & 8.93 \\
\hline $\mathrm{Na}(\%)$ & 0.06 & - \\
\hline Al (\%) & - & 0.08 \\
\hline$P(\%)$ & 2.22 & 37.19 \\
\hline S (\%) & 0.36 & 0.10 \\
\hline$K(\%)$ & 0.27 & 0.19 \\
\hline $\mathrm{Ca}(\%)$ & 2.38 & 0.32 \\
\hline $\mathrm{Cr}(\%)$ & 1.11 & 1.64 \\
\hline Mn (\%) & 0.14 & 0.10 \\
\hline Fe (\%) & 6.83 & 5.77 \\
\hline Co (\%) & 0.01 & 0.01 \\
\hline $\mathrm{Ni}(\%)$ & 0.38 & 0.41 \\
\hline $\mathrm{Cu}(\%)$ & 0.02 & 0.03 \\
\hline Zn (\%) & 14.45 & 0.07 \\
\hline Mo (\%) & 0.06 & 0.27 \\
\hline $\mathrm{Cl}(\%)$ & 0.32 & - \\
\hline $\mathrm{Ba}(\%)$ & - & 0.05 \\
\hline
\end{tabular}

a) Surface area obtained from $\mathrm{N}_{2}$ adsorption isotherms at $77 \mathrm{~K}$.

b) External surface area obtained by mercury porosimetry.

c) Pore's volume (diameter of $6.6-50 \mathrm{~nm}$ ) obtained by mercury porosimetry.

d) Pore's volume (diameter $>50 \mathrm{~nm}$ ) obtained by mercury porosimetry.

e) The volume of pores accessible to water determined by pycnometric densities.

$\mathrm{f}, \mathrm{g}$ ) Volumes of micropores obtained by $\mathrm{N}_{2}$ and $\mathrm{CO}_{2}$ adsorption, respectively.

$\mathrm{h}, \mathrm{i})$ Mean widths of micropores by $\mathrm{N}_{2}$ and $\mathrm{CO}_{2}$ adsorption, respectively, determined with the Dubinin equation.

j) The concentration of acidic groups determined by titration with $\mathrm{NaOH}(0.1 \mathrm{~N})$.

k) The concentration of basic groups determined by titration with $\mathrm{HCl}(0.1 \mathrm{~N})$.

I) $\mathrm{pH}$ of the point of zero charge.

m) Oxygen content by weight

n) Obtained at $900^{\circ} \mathrm{C}$ model, b) $\mathrm{q}_{\text {pred,2 }}$ values were more similar to $\mathrm{q}_{\exp }$ than $\mathrm{q}_{\text {pred,1 }}$ for all runs. These results show that the second-order model correlates to the experimental adsorption data much better than the first-order model.

Further, the adsorption kinetic constants were higher for carbon RSZ than those for RSP. This may be related to its higher volume of micropores and larger surface area than those for RSP. The adsorption rate of the activated carbons is relatively decreasing (MCPA > 2,4-D > DPA). Note the inverse proportion between absorption rate vs pollutant molecular size, MCPA of being smaller molecular size than DPA, see Table (1)

\section{Adsorption isotherm.}

Figure 1 represents the adsorption isotherm of DPA, 2,4-D and MCPA on carbons RSZ and RSP. Isotherm

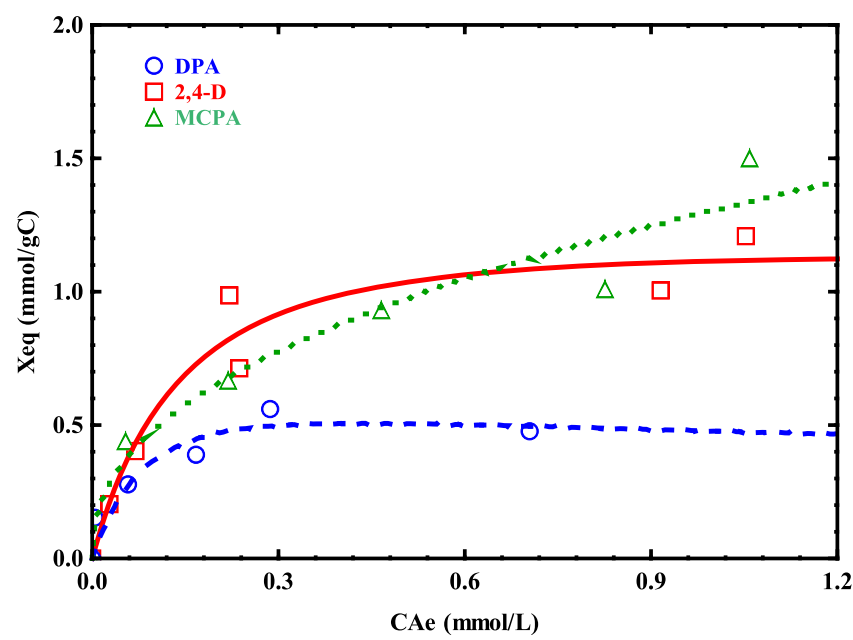

a)

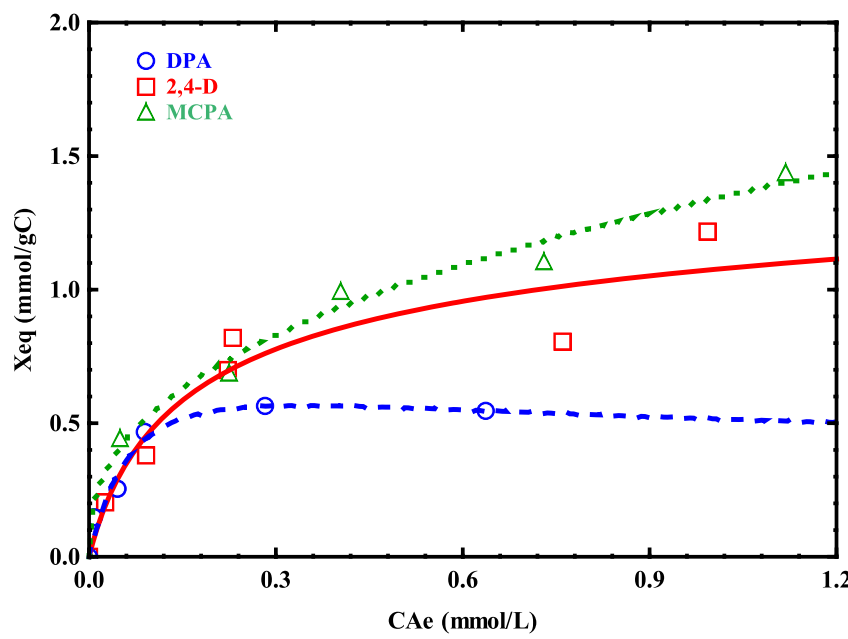

b)

Figure 1. Adsorption isotherm of DPA, 2,4-D and MCPA on carbon samples a) RSZ and b) RSP, $\mathrm{pH}=3.20$ and $\mathrm{T}=298$ Kcarbon samples a) RSZ and b) RSP, $\mathrm{pH}=3.20$ and $\mathrm{T}=298 \mathrm{~K}$

Table 3. Adsorption kinetic data after applying pseudo first and second order models to the selected pollutants on activated carbons RSZ and RSP

\begin{tabular}{|c|c|c|c|c|c|c|c|c|}
\hline \multirow[b]{2}{*}{ Pollutant } & \multirow[b]{2}{*}{ Carbon } & \multirow[b]{2}{*}{$\underset{[\mathrm{mmol} / \mathrm{g}]}{q_{\exp }}$} & \multicolumn{3}{|c|}{ Pesudo $1^{\text {st }}$ order } & \multicolumn{3}{|c|}{ Pesudo $2^{\text {nd }}$ order } \\
\hline & & & $\begin{array}{c}q_{\text {pred,1 }} \\
{[\mathrm{mmol} / \mathrm{g}]}\end{array}$ & $\begin{array}{c}k_{1} \\
{[1 / h]}\end{array}$ & $\mathbf{R}^{2}$ & $\begin{array}{c}\mathbf{q}_{\text {pred,2 }} \\
{[\mathrm{mmol} / \mathrm{g}]}\end{array}$ & $\begin{array}{c}\mathbf{k}_{2} \times 10^{2} \\
{[\mathrm{~g} / \mathrm{mmol} / \mathrm{h}]}\end{array}$ & $\mathbf{R}^{2}$ \\
\hline \multirow{2}{*}{ DPA } & RSZ & 0.26 & 0.24 & 0.37 & 0.914 & 0.26 & 0.78 & 0.998 \\
\hline & RSP & 0.24 & 0.23 & 0.16 & 0.851 & 0.25 & 0.34 & 0.997 \\
\hline \multirow{2}{*}{ 2,4-D } & RSZ & 0.34 & 0.32 & 0.46 & 0.881 & 0.34 & 2.31 & 0.976 \\
\hline & RSP & 0.32 & 0.31 & 0.42 & 0.855 & 0.33 & 2.20 & 0.999 \\
\hline \multirow{2}{*}{ MCPA } & RSZ & 0.39 & 0.32 & 1.77 & 0.939 & 0.35 & 10.68 & 0.999 \\
\hline & RSP & 0.39 & 0.31 & 1.43 & 0.931 & 0.34 & 7.26 & 0.996 \\
\hline
\end{tabular}


depicts the $\mathrm{L}$ form of Giles classification ${ }^{35,36}$, proposing that; a) the aromatic rings of all pollutant molecules were adsorbed in parallel to the surface of carbon, b) there is no major rivalry between pollutant molecules and water molecules for the active adsorption centers on the carbon.

Langmuir, Freundlich and Prausnitz-Radke adsorption isotherm model equations (9-11) are the most widely used models for this type of process:

$\mathrm{X}_{\mathrm{eq}}=\frac{\mathrm{BX}_{\mathrm{m}} \mathrm{C}_{\mathrm{Ae}}}{1+\mathrm{BC}_{\mathrm{Ae}}}$

$\mathrm{X}_{\mathrm{eq}}=\mathrm{K}_{\mathrm{F}} \mathrm{C}_{\mathrm{Ae}}^{1 / \mathrm{nF}}$

$\mathrm{q}=\frac{\mathrm{aC}_{\mathrm{A}}}{1+\mathrm{bC}_{\mathrm{A}}^{\beta}}$

These equations were used to evaluate the experiment results of the study to determine the type and mechanism of the adsorption processes. The adsorption isotherms model constants were evaluated by using a non-linear estimation method with Statistica software (release 7). The values of the isotherm constants as well as the average absolute percentage deviations are given in Table 4 by using the following equation:

$\% \mathrm{D}=\frac{1}{\mathrm{~N}} \sum_{\mathrm{i}=1}^{\mathrm{N}}\left|\frac{\mathrm{q}_{\text {exp }}-\mathrm{q}_{\text {pred }}}{\mathrm{q}_{\exp }}\right| \times 100 \%$

The comparison between Langmuir, Freundlich and Prausnitz-Radke models was presented at Table (4), Langmuir model fits the experiment data of DPA much better than other models with an average percentage deviations of less than $9.71 \%$ followed by Freundich (17.15\%) and Prausnitz-Radke (19.67\%). However, the Prausnitz-Radke model fits better to the experiment data of 2,4-D and MCPA than other models. Prausnitz-Radke model's average percentage deviation is less than $10.80 \%$ and $7.76 \%$ for 2,4-D and MCPA, respectively. This means that the adsorption of DPA into both activated carbons were monolayer and the adsorption of 2,4-D and MCPA is monolayer and multilayer hybrid. This explains the resulting order of adsorption rate of: a) MCPA the highest b) 2,4-D the second highest and c) DPA the lowest.
Taking a sample from Table 4 , a relatively high maximum adsorption capacity $\left(\mathrm{X}_{\mathrm{m}}\right)$ : a) $\mathrm{MCPA}=1.64,2,4-\mathrm{D}$ $=1.27$, and DPA $=0.54 \mathrm{mmol} / \mathrm{g}$ on carbon RSZ b) $\mathrm{MCPA}=1.64,2,4-\mathrm{D}=1.23$, and $\mathrm{DPA}=0.61 \mathrm{mmol} / \mathrm{g}$ on carbon RSP. This shows that the adsorption capacity of carbon RSZ and carbon RSP for all pollutants, despite the surface area and volumes of micropores of both carbons, were approximately equal.

In previous works, Méndez-Díaz et al. ${ }^{30}$ provided an extensive discussion on the adsorption mechanism of aromatic compounds on activated carbon. Establishing the dispersive interactions between $\pi$ electrons of the graphene planes of the activated carbon surface. $\pi$ electrons of the aromatic ring provide for this process. Note the ascending value of the adsorption capacity of both activated carbons - DPA $<2,4$-D $<$ MCPA. This is due to the use of two aromatic rings of DPA that effectively diminishes their electronic density. Note that the adsorbent-adsorbate interactions introduce resistance to the adsorption process.

The quantity of MCPA adsorbed was the highest. This is mainly due to MCPA having the smallest molecular size while DPA has the largest (Table 1). This makes these molecules to approach the smaller micropores size $\left(\mathrm{L}_{\mathrm{o}}\left(\mathrm{CO}_{2}\right)\right)$ (Table 2). Thus, the lower values of adsorbent-adsorbate relative affinity $\left(\mathrm{BX}_{\mathrm{m}}\right)$ for DPA compared to MCPA.

Table 5 shows the occupied area augmentation order $\mathrm{S}_{\mathrm{DPA}}<\mathrm{S}_{2,4-\mathrm{D}}<\mathrm{S}_{\mathrm{MCPA}}$ for both activated carbons (RSZ and RSP). The maximum occupied area was of MCPA molecules: $\mathrm{RSZ}=79.43 \%, \mathrm{RSP}=99.91 \%$. These confirms that the adsorption of MCPA on both carbons was monolayer and multilayer. However, the occupied area was lower for 2,4-D and DPA: $61.51 \%$ and $32.48 \%$ for carbon RSZ; $74.93 \%$ and $46.15 \%$ for carbon RSP.

Table 5. The occupied surface area by adsorbed molecules on the surface of activated carbons

\begin{tabular}{|l|l|c|c|}
\hline Pollutant & Carbon & $\mathbf{S}_{\mathrm{o}}{ }^{a)}$ & $\mathbf{S}_{\mathrm{o}} / \mathbf{S}_{\mathbf{N} 2} \mathbf{\times 1 0 0} \%$ \\
\hline \multirow{2}{*}{ DPA } & RSZ & 250.44 & 32.48 \\
\cline { 2 - 4 } & RSP & 282.90 & 46.15 \\
\hline \multirow{2}{*}{ 2,4-D } & RSZ & 474.25 & 61.51 \\
\cline { 2 - 4 } & RSP & 459.31 & 74.93 \\
\hline \multirow{2}{*}{ MCPA } & RSZ & 612.42 & 79.43 \\
\cline { 2 - 4 } & RSP & 612.42 & 99.91 \\
\hline
\end{tabular}

a) So: The occupied surface by adsorbed molecules

Table 4. Parameters obtained by applying the Langmuir, Freundlich and Prausnitz-Radke equations adsorption isotherms of selected pollutants on carbons RSZ and RSP

\begin{tabular}{|c|c|c|c|c|c|c|c|c|c|c|c|c|c|}
\hline \multirow[b]{2}{*}{ Pollutant } & \multirow[b]{2}{*}{ C } & \multicolumn{5}{|c|}{ Langmuir } & \multicolumn{3}{|c|}{ Freundlich } & \multicolumn{4}{|c|}{ Prausnitz-Radke } \\
\hline & & $\begin{array}{c}\mathrm{X}_{\mathrm{m}}{ }^{\mathrm{a}} \\
{[\mathrm{mmol} / \mathrm{g}]}\end{array}$ & $\begin{array}{c}\mathrm{B}^{\mathrm{b})} \\
{[\mathrm{L} / \mathrm{mmol}]}\end{array}$ & $\begin{array}{c}\left.\mathrm{BX}_{\mathrm{m}}{ }^{\mathrm{c}}\right) \\
{[\mathrm{L} / \mathrm{g}]}\end{array}$ & $\begin{array}{c}X_{m}^{\prime} \times 10^{-4} \\
{\left[\mathrm{mmol} / \mathrm{m}^{2} / \mathrm{g}\right]}\end{array}$ & $\% \mathrm{D}$ & $\begin{array}{l}\mathrm{K}_{\mathrm{F}}{ }^{\mathrm{d})} \\
{[\mathrm{L} / \mathrm{g}]}\end{array}$ & $1 / n_{F}{ }^{e)}$ & $\% \mathrm{D}$ & $\begin{array}{c}a^{f)} \\
{[L / g]}\end{array}$ & $\begin{array}{c}b^{\mathrm{g})} \\
{\left[\mathrm{L}^{\beta} / \mathrm{mmol}^{\beta}\right]}\end{array}$ & $\beta^{\text {h) }}$ & $\% D$ \\
\hline \multirow{2}{*}{ DPA } & RSZ & 0.54 & 23.35 & 12.61 & 7.00 & 9.71 & 0.58 & 0.22 & 9.73 & 6.59 & 0.01 & 1.21 & 19.67 \\
\hline & RSP & 0.61 & 25.23 & 15.39 & 9.95 & 4.12 & 0.68 & 0.25 & 17.15 & 9.20 & 0.02 & 1.22 & 13.35 \\
\hline \multirow{2}{*}{ 2,4-D } & RSZ & 1.27 & 7.81 & 9.92 & 16.47 & 10.50 & 1.16 & 0.33 & 19.43 & 8.37 & 0.02 & 1.09 & 8.73 \\
\hline & RSP & 1.23 & 6.11 & 7.52 & 20.07 & 11.96 & 1.12 & 0.38 & 17.82 & 9.47 & 0.06 & 0.90 & 10.80 \\
\hline \multirow{2}{*}{ MCPA } & RSZ & 1.64 & 3.34 & 5.48 & 21.27 & 14.68 & 1.31 & 0.43 & 7.91 & 241888.00 & 8169.57 & 0.59 & 7.76 \\
\hline & RSP & 1.64 & 3.86 & 6.33 & 26.75 & 11.38 & 1.31 & 0.40 & 5.21 & 453140.00 & 13037.50 & 0.61 & 5.15 \\
\hline
\end{tabular}

a) $X_{m}$ : Adsorption capacity

b) B: Langmuir constant

c) $\mathrm{BX}_{\mathrm{m}}$ : Adsorbent-adsorbate relative affinity

d) $\mathrm{K}_{\mathrm{F}}$ : Relative adsorption capacity

e) $1 / n_{F}$ : Sorption intensity or surface heterogeneity

f) Prausnitz-Radke isotherm constant, $\mathrm{L} / \mathrm{g}$

g) Prausnitz-Radke isotherm constant, $\mathrm{L}^{\beta} / \mathrm{mmol}^{\beta}$

h) Prausnitz-Radke isotherm constant 
These results further confirm that there are areas that molecules cannot access due to hindering effects.

\section{Diffusion models}

The external mass transport parameters must be determined first before correlating the adsorption kinetic data to the diffusional model. The molecular diffusion coefficient of pollutants in aqueous solution was assessed by using the equation ${ }^{37}$ :

$\mathrm{D}_{\mathrm{AB}}=\frac{7.4 \times 10^{-8}\left(\phi \mathrm{M}_{\mathrm{B}}\right)^{1 / 2} \mathrm{~T}}{\eta_{\mathrm{b}} \mathrm{V}_{\mathrm{A}}^{0.6}}$

Where: $\phi=2.60, \mathrm{M}_{\mathrm{B}}=18 \mathrm{~g} / \mathrm{mol}, \eta_{\mathrm{b}}=0.89 \mathrm{cp}$. Le Bas method [38] was used to estimate the $V_{A}$ values of DPA, 2,4-D and MCPA. These are provided in Table 1. The derived molecular diffusion coefficient is: a) DPA $-5.37 \times 10^{-6}$, b) $2,4-\mathrm{D}-7.46 \times 10^{-6}$ and c) MCPA $-7.38 \times 10^{-6} \mathrm{~cm}^{2} / \mathrm{s}$.

Furusawa and $\mathrm{Smith}^{39}$, proposed the procedure to assess the experimental external mass transfer coefficient based on the following conditions; $\mathrm{t} \rightarrow 0, \mathrm{C}_{\mathrm{Ar}} \rightarrow 0$ and $\mathrm{C}_{\mathrm{A}} \rightarrow \mathrm{C}_{\mathrm{A} 0}$. If these conditions are introduced into equation (3), the equation below is derived:

$\left[\frac{\mathrm{d}\left(\frac{\mathrm{C}_{\mathrm{A}}}{\mathrm{C}_{\mathrm{A} 0}}\right)}{\mathrm{dt}}\right]_{\mathrm{t}=0}=\frac{-\mathrm{mSk}_{\mathrm{L}, \exp }}{\mathrm{V}}$

The term at the right of equation (14) is the rate of concentration decay at $\mathrm{t}=0$. This rate of decay was estimated using points $t=0$ and $t=5$ min of the concentration decay curve.

The experimental values of $\mathrm{k}_{\mathrm{L} \text {,exp }}$ obtained are listed in Table 6. The highest was observed in the case of MCPA followed by $2,4-\mathrm{D}$ then by finally DPA. These confirm the results obtained from adsorption kinetics.

Pore volume diffusion model (PVDM) considers that that intraparticle diffusion is due to pore volume diffusion mechanisms. The relationship between the effective diffusion coefficient $\left(\mathrm{D}_{\mathrm{ep}}\right)$ in a porous material and the molecular diffusivity $\left(\mathrm{D}_{\mathrm{AB}}\right)$ can be described by various models. The simplest and commonly used model is based on the tortuosity factor, $\tau$. In this model, $\mathrm{D}_{\mathrm{ep}}$ can be estimated from the equation ${ }^{40-42}$.

$\mathrm{D}_{\mathrm{ep}}=\frac{\mathrm{D}_{\mathrm{AB}} \varepsilon_{\mathrm{p}}}{\tau}$

Leyva-Ramos and Geankoplis ${ }^{28}$; Méndez-Díaz et $\mathrm{al}^{\mathbf{3 0}}$ and Leyva-Ramos et al., ${ }^{43}$ studied intraparticle diffusion of organic compounds in activated carbons and recommended a tortuosity of $\tau=3.5$ from a derived range of 1.57 to 6.57 .

\section{Numerical solution of the diffusion model}

To start solving the diffusion equations (3) to (8), dimensionless variables are used to transform the diffusion model into a dimensionless model. Then a discretization step is performed to establish the finite difference approximation of the model. The dimensionless model is given as:

$\frac{\mathrm{d} \phi_{\mathrm{A}}}{\mathrm{d} \theta}=-\frac{\mathrm{mSR}_{\mathrm{p}}^{2} \mathrm{k}_{\mathrm{L}, \exp }}{\mathrm{VD}_{0}}\left(\phi_{\mathrm{A}}-\left.\eta_{\mathrm{A}}\right|_{\xi=1}\right)$

$\theta=0, \quad \phi_{\mathrm{A}}=1$

$\frac{\partial \eta_{\mathrm{A}}}{\partial \theta}=\frac{1}{(1+\chi \omega)\left[\varepsilon_{\mathrm{p}}+\omega \hat{\mathrm{F}}\left(\eta_{\mathrm{A}}\right)\right]} \frac{1}{\xi^{2}} \frac{\partial}{\partial \xi}\left[\xi^{2}\left(1+\chi \omega \hat{\mathrm{F}}\left(\eta_{\mathrm{A}}\right)\right) \frac{\partial \eta_{\mathrm{Ar}}}{\partial \xi}\right]$

$\eta_{\mathrm{A}}=0, \quad \theta=0, \quad 0 \leq \xi \leq 1$

$\left.\frac{\partial \eta_{\mathrm{A}}}{\partial \theta}\right|_{\xi=0}=0$

$\left.\frac{\partial \eta_{\mathrm{A}}}{\partial \xi}\right|_{\xi=1}=\frac{(1+\chi \omega) \mathrm{R}_{\mathrm{p}} \mathrm{k}_{\mathrm{L}, \exp }}{\mathrm{D}_{0}\left[1+\left.\chi \omega \hat{\mathrm{F}}\left(\eta_{\mathrm{A}}\right)\right|_{\xi=1}\right]}\left(\left.\emptyset_{\mathrm{A}-\eta_{\mathrm{A}}}\right|_{\xi=1}\right)$

The radius of pores is discretized into $\mathrm{N}$ points with (N-1) distances. The mathematical model (16)-(21) consists of two coupled differential equation with mixed boundary conditions. The first equation is a first order ordinary differential equation in time variable while the other is a second order, parabolic, nonlinear partial differential equation. The coupled system relates the diffusion of concentration through the ambient solution to the diffusion through the pores and surfaces of nanoparticles. The numerical technique that has been used is finite difference with forward time forward space (FTFS) implementation where the normalized radius of the particle is divided linearly into $\mathrm{N}$ points with step $\Delta \xi$ and normalized time step $\Delta \theta$.

The first derivative at any point (i) with respect to dimensionless time, $\theta$, is defined by $\frac{\partial \eta_{A}}{\partial \theta}=\frac{\eta_{A(\mathrm{i})}^{n+1}-\eta_{A(\mathrm{i})}^{n}}{\Delta \theta}$ while the first and second derivatives with respect to dimensionless spatial variable at time $(\mathrm{n})$ are given by $\frac{\partial \eta_{A r}}{\partial \xi}=\left(\frac{-3 \eta_{A(i)}^{n}+4 \eta_{A(i+1)}^{n}-\eta_{A(i+2)}^{n}}{2 \Delta \xi}\right), \frac{\partial^{2} \eta_{A r}}{\partial \xi^{2}}=\left(\frac{\eta_{A(i+1)}^{n}+\eta_{A(i-1)}^{n}-2 \eta_{A(i)}^{n}}{(\Delta \xi)^{2}}\right)$. the discretized model is given by

$$
\begin{aligned}
& \frac{\phi_{A}^{n+1}-\phi_{A}^{n}}{\Delta \theta}=-\frac{m R_{p}^{2} k_{L, \exp }}{\operatorname{VD}_{0}}\left(\phi_{A}^{n}-\left.\eta_{A}^{n}\right|_{\xi=1}\right) \\
& \left.\frac{\eta_{A(i)}^{n+1}-\eta_{A(i)}^{n}}{\Delta \theta}=\frac{1}{(1+\chi \omega)\left[\varepsilon_{p}+\omega \hat{F}\left(\eta_{A(i)}^{n}\right)\right.}\right]\left[\begin{array}{l}
\frac{2}{\xi_{i}}\left(1+\chi \omega \hat{F}\left(\eta_{A(i)}^{n}\right)\right)\left(\frac{-3 \eta_{A(i)}^{n}+4 \eta_{A(i+1)}^{n}-\eta_{A(i+2)}^{n}}{2 \Delta \xi}+\left(1+\chi \omega \hat{F}\left(\eta_{A(i)}^{n}\right)\right)\left(\frac{\eta_{A(i+1)}^{n}+\eta_{A(i-1)}^{n}-2 \eta_{A(i)}^{n}}{(\Delta \xi)^{2}}\right)\right. \\
+\left(\chi \omega \hat{F}\left(\eta_{A(i)}^{n}\right)\right)\left(\frac{-3 \eta_{A(i)}^{n}+4 \eta_{A(i+1)}^{n}-\eta_{A(i+2)}^{n}}{2 \Delta \xi}\right)^{2}
\end{array}\right]
\end{aligned}
$$

\begin{tabular}{|c|c|c|c|c|c|c|c|}
\hline Pollutant & Carbon & $\begin{array}{c}\mathrm{C}_{\mathrm{A0}} \\
{[\mathrm{mg} / \mathrm{L}]}\end{array}$ & $\begin{array}{c}\mathrm{C}_{\mathrm{Ae}} \\
{[\mathrm{mg} / \mathrm{L}]}\end{array}$ & $\begin{array}{c}q_{e} \\
{[\mathrm{mg} / \mathrm{g}]}\end{array}$ & $\begin{array}{c}k_{L, \exp } \times 10^{3} \\
{[\mathrm{~cm} / \mathrm{s}]}\end{array}$ & $\begin{array}{l}D_{\text {ep }} \times 10^{7} \\
{\left[\mathrm{~cm}^{2} / \mathrm{s}\right]}\end{array}$ & $\mathbf{T}$ \\
\hline \multirow{2}{*}{ DPA } & RSZ & 96.02 & 16.80 & 79.23 & 0.72 & 4.31 & 2.27 \\
\hline & RSP & 86.82 & 13.30 & 73.51 & 0.27 & 2.69 & 3.63 \\
\hline \multirow{2}{*}{ 2,4-D } & RSZ & 104.40 & 15.36 & 89.04 & 0.79 & 4.52 & 3.00 \\
\hline & RSP & 101.52 & 20.28 & 81.24 & 0.77 & 4.85 & 2.89 \\
\hline \multirow{2}{*}{ MCРA } & RSZ & 102.18 & 10.35 & 91.83 & 0.77 & 7.38 & 1.81 \\
\hline & RSP & 102.18 & 9.82 & 92.36 & 1.09 & 2.21 & 6.04 \\
\hline
\end{tabular}

Table 6. Calculation of mass transfer coefficient, diffusion coefficient, and tortuosity factor for investigated experiments 
with boundary and initial conditions:

$$
\begin{aligned}
& \phi_{\mathrm{A}}^{0}=1, \eta_{\mathrm{A}(\mathrm{i})}^{0}=0, \quad-3 \eta_{\mathrm{A}(1)}^{0}+4 \eta_{\mathrm{A}(2)}^{0}-\eta_{\mathrm{A}(3)}^{0}=0 \\
& \frac{-4 \eta_{\mathrm{A}(\mathrm{N}-1)}^{\mathrm{n}+1}+\eta_{\mathrm{A}(\mathrm{N}-2)}^{\mathrm{n}}+3 \eta_{\mathrm{A}(\mathrm{N})}^{\mathrm{n}}}{\Delta \xi}=\frac{(1+\chi \omega) \mathrm{R}_{\mathrm{p}} \mathrm{k}_{\mathrm{L}, \mathrm{exp}}}{\mathrm{D}_{0}\left[1+\chi \omega \mathrm{F}\left(\eta_{\mathrm{A}(\mathrm{N})}^{\mathrm{n}}\right)\right]}\left(\phi_{\mathrm{A}}^{\mathrm{n}}-\eta_{\mathrm{A}(\mathrm{N})}^{\mathrm{n}}\right)
\end{aligned}
$$

To check the stability of the method, Von Neumann method is applied to check the stability. Replace $\eta_{\mathrm{A}(\mathrm{i})}^{\mathrm{n}+1}=\eta_{\mathrm{A}(\mathrm{i})}^{\mathrm{n}} \mathrm{e}^{\mathrm{i} \psi}, \eta_{\mathrm{A}(\mathrm{i}+1)}^{n_{1}}=\eta_{\mathrm{A}(\mathrm{i})}^{\mathrm{n}} \mathrm{e}^{\mathrm{i} \psi}, \eta_{\mathrm{A}(\mathrm{i}-1)}^{\mathrm{n}}=\eta_{\mathrm{A}(\mathrm{i})}^{\mathrm{n}} \mathrm{e}^{-i \psi}, \eta_{\mathrm{A}(\mathrm{i}+2)}^{\mathrm{n}}=\eta_{\mathrm{A}(\mathrm{i})}^{\mathrm{n}} \mathrm{e}^{\mathrm{i} 2 \psi}$ i $\mathrm{n}$ equation (22) and (23). Equation (22) is transformed to $\phi_{A}^{n+1}=\phi_{A}^{n}-\frac{\Delta \theta \mathrm{mSR}_{\mathrm{p}}^{2} \mathrm{k}_{\mathrm{L}, \mathrm{xxp}}}{\mathrm{VD}_{0}}\left(\phi_{\mathrm{A}}^{\mathrm{n}}-\left.\eta_{\mathrm{A}}^{\mathrm{n}}\right|_{\xi=1}\right)$. From which assuming neglected surface concentration one can get $G=\frac{\phi_{A}^{n+1}}{\phi_{A}^{n}}=1-\frac{\Delta \theta \mathrm{mSR}_{\mathrm{R}} \mathrm{K}_{\mathrm{L}, \text { exp }}}{\mathrm{VD}_{0}}$. To satisfy stability, then $|G|<1$ which is satisfied. But for accurate calculations, we restricted the condition to be

$\frac{\Delta \theta\left(\mathrm{mSR}_{\mathrm{p}}^{2} \mathrm{k}_{\mathrm{L}, \mathrm{exp}}\right)}{\mathrm{VD}_{0}} \leq \frac{1}{2}$

So, the time step $(\Delta \theta)$ is chosen to satisfy the previous condition. By the same way, equation (23) is satisfied by the same condition.

Pore volume diffusion model (PVDM) by assuming $\left(\mathbf{D}_{\mathrm{ep}} \neq \mathbf{0}, \mathbf{D}_{\mathrm{s}}=\mathbf{0}\right)$

The PVDM model was used to interpret the derived experimental concentration decay curves. The mass transport parameters required to solve this model were $\mathrm{D}_{\text {ep }}$ and $\mathrm{k}_{\mathrm{L} \text {,exp }}$. $D_{\text {ep }}$ was determined with equation (15) using $\tau=3.5$ and $\mathrm{k}_{\mathrm{L} \text {,exp }}$ was calculated using equation (14). The optimal value of $D_{e p}$ is obtained by taking the numerical solution of the PVDM model $\left(\emptyset_{\text {pred }}\right)$ with the experimental concentration decay data then minimize the function:

Minimum $=\sum_{1}^{\mathrm{N}}\left(\emptyset_{\mathrm{exp}}-\emptyset_{\text {pred }}\right)^{2}$

The optimum values of $\mathrm{D}_{\mathrm{ep}}$ and the corresponding $\tau$ values were shown in Table $6 . \mathrm{D}_{\mathrm{ep}}$ values were in the range of $2.21 \times 10^{-7}$ to $4.85 \times 10^{-7} \mathrm{~cm}^{2} / \mathrm{s}$ except for the case of MCPA on RSZ which was a little higher $\left(7.38 \times 10^{-7} \mathrm{~cm}^{2} / \mathrm{s}\right)$

PVDM model with the derived optimal $\mathrm{D}_{\text {ep }}$ can predict points in the experimental data better than the same model using initial $\mathrm{D}_{\mathrm{ep}}$ values at $\tau=3.50$. It is safe to conclude that, for the studied systems, both methods are accurate in predicting data points in the experimental data. The tortuosity factor values in this study range from 1.81 to 6.04 .

Surface diffusion model (SDM) by assuming $\left(\mathrm{D}_{\mathrm{ep}}=\mathbf{0}\right.$, $\mathbf{D}_{\mathrm{s}} \neq \mathbf{0}$ )

Surface diffusion model (SDM) considers that intraparticle diffusion is due to the surface diffusion mechanisms. It was calculated according to equation (8) by neglecting the part of pore volume diffusion.

Pore volume surface diffusion model (PVSDM) by assuming $\left(D_{\text {ep }} \neq 0, D_{\mathrm{s}} \neq 0\right)$

Pore volume and surface diffusion model (PVSDM) considers that intraparticle diffusion is due to both pore volume and surface diffusion mechanisms. In order to solve the PVSDM model, $\mathrm{k}_{\mathrm{L}, \text { exp }}$ was calculated from equation (14) with an optimum $\mathrm{D}_{\mathrm{ep}}$ derived from PVDM to minimize the error. Hence, the surface diffusion coefficient $\left(D_{s}\right)$ was the remaining parameter to evaluate. To do this, a numerical solution of the PVSDM model (eq. 27) using concentration decay data was derived then iterated for different values of $\mathrm{D}_{\mathrm{s}}$ until it converges (minimum error). Figure 2 is a depiction of the experimental concentration decay data of MCPA onto RSZ and RSP. The figure shows that from the corresponding concentration decay curves of PVDM, SDM, and PVSDM, the best value of $\tau$ is obtained by PVDM. It is worth noticing that the PVDM and PVSDM models interpret the experimental data very satisfactorily.

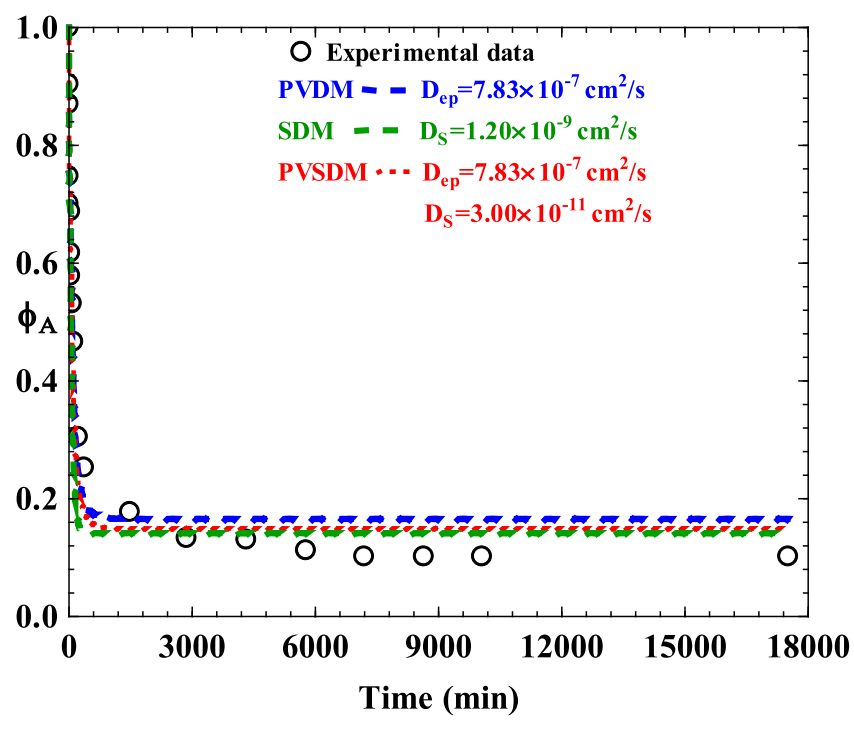

a)

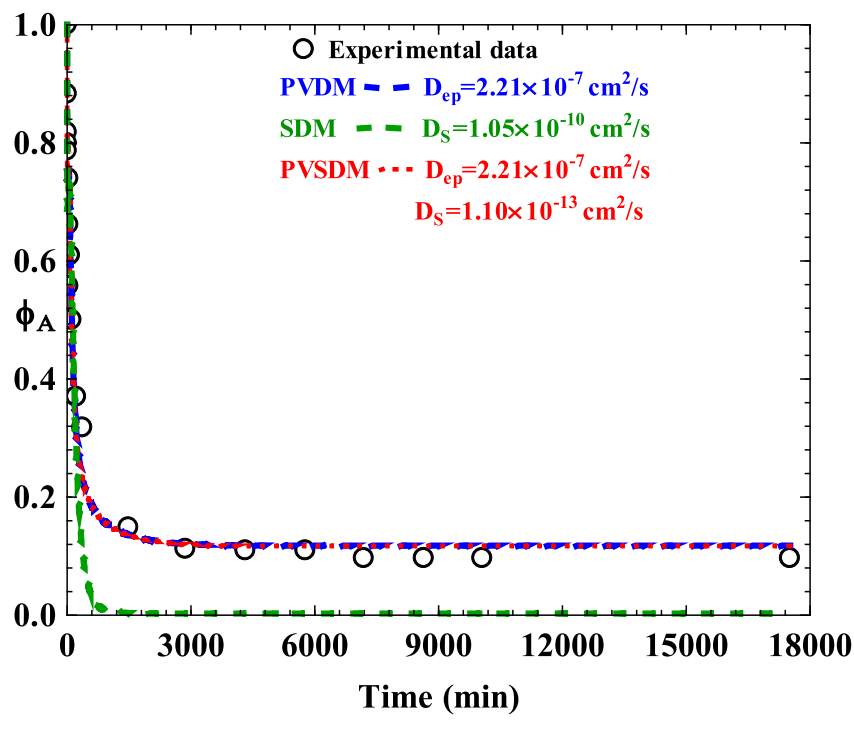

b)

Figure 2. Concentration decay curves for MCPA adsorption on activated carbons a) RSZ and b) RSP

The overall intraparticle diffusion of the different pollutants studied was evaluated. Specifically, the relative contribution of each diffusion mechanism in the said diffusion process. The following equations were used to estimate the mass transport due to pore volume diffusion $\left(\mathrm{N}_{\mathrm{AP}}\right)$ and surface diffusion $\left(\mathrm{N}_{\mathrm{AS}}\right)$ :

$\mathrm{N}_{\mathrm{AP}}=-\mathrm{D}_{\mathrm{ep}} \frac{\partial \mathrm{C}_{\mathrm{Ar}}}{\partial \mathrm{r}}$

$\mathrm{N}_{\mathrm{AS}}=-\mathrm{D}_{\mathrm{s}} \rho_{\mathrm{p}} \frac{\partial \mathrm{q}}{\partial \mathrm{r}}$

The equation below was then used to estimate the relative contribution of pore volume diffusion to the overall intraparticle diffusion: 
$\frac{\mathrm{N}_{\mathrm{AP}}}{\mathrm{N}_{\mathrm{AS}}+\mathrm{N}_{\mathrm{AP}}}=\frac{\mathrm{D}_{\mathrm{ep}} \frac{\partial \mathrm{C}_{\mathrm{Ar}}}{\partial \mathrm{r}}}{\mathrm{D}_{\mathrm{s}} \rho_{\mathrm{p}} \frac{\partial \mathrm{q}}{\partial \mathrm{r}}+\mathrm{D}_{\mathrm{ep}} \frac{\partial \mathrm{C}_{\mathrm{Ar}}}{\partial \mathrm{r}}}$

The results are then plotted (Figure 3 ) using the following dimensionless radial positions; $\xi(\mathrm{r} / \mathrm{R})(0 / 6,1 / 6,2 / 6$, $3 / 6,4 / 6,5 / 6$, and $6 / 6)$. Note that figure 3 is a plot just for MCPA on both activated carbons. The results revealed that the contribution of pore volume diffusion is over $85 \%$ for RSZ and 99\% for RSP. These are percentages from the overall intraparticle diffusion as a function of the radial position and time. Note that from the rest of the systems studied; a) DPA on RSP that started at $42 \%$, b) all else, the contribution of pore volume was more than $99 \%$. Hence, pore volume diffusion is dominant in intraparticle diffusion of selected micropollutants during adsorption into activated carbon samples RSZ and RSP. In the succeeding sections, experimental adsorption data will be interpreted using PVDM model.

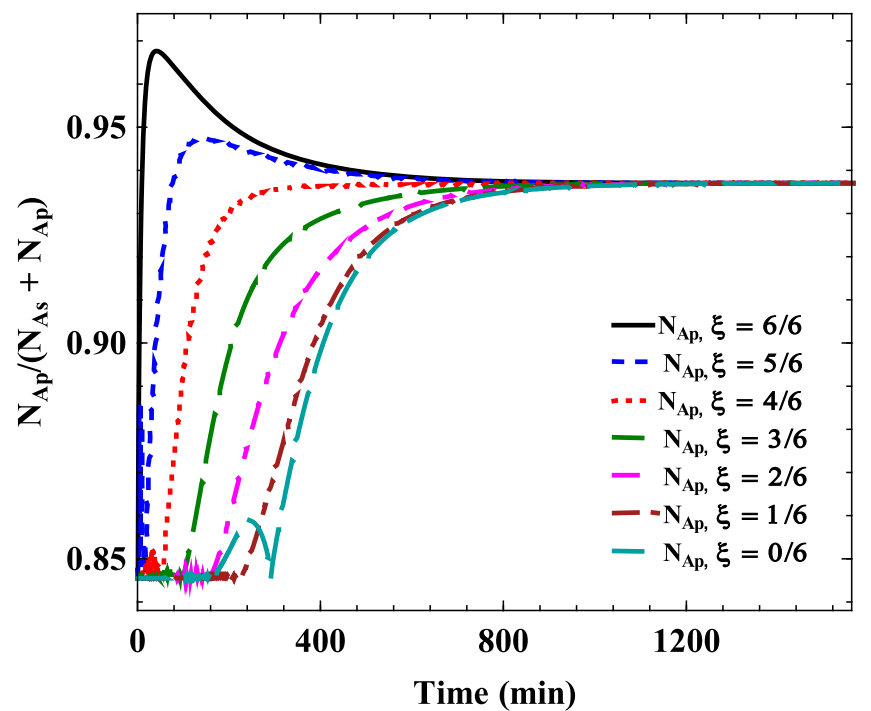

a)

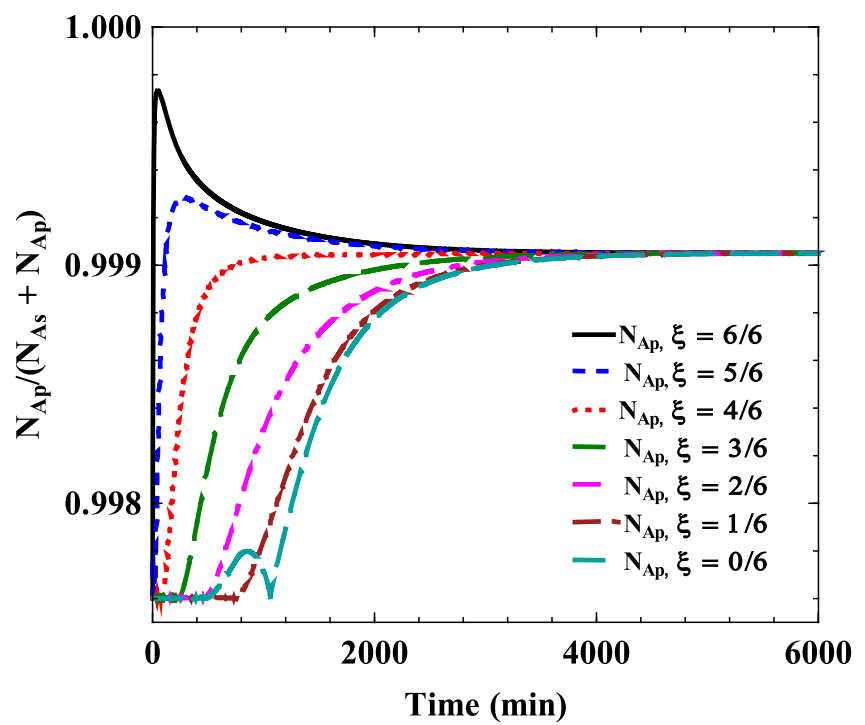

b)

Figure 3. Contribution of pore volume diffusion to intraparticle diffusion at different radial position for MCPA adsorption on activated carbons a) RSZ and b) RSP
Effect of solution pH and Ionic Strength on adsorption process.

\section{Influence of solution $\mathbf{p H}$}

One of the most important parameters in the adsorption process is the solution's $\mathrm{pH}$. Figure $4 \mathrm{a}$ ) and b) represent the influence of solution $\mathrm{pH}$ on the adsorption of 2,4D, DPA and MCPA into carbons RSZ and RSP. The solution's $\mathrm{pH}$ evidently influence the adsorption process. The highest adsorption capacity for both carbons were at $\mathrm{pH}(4,3$, and 3) for DPA, 2,4-D and MCPA, respectively. Adsorption capacity is then diminished gradually by increasing the solution $\mathrm{pH}$. It should be noted that aside from the solution $\mathrm{pH}$, electrostatic interactions also play a significant role in the adsorption processes. Note that the solution $\mathrm{pH}$ is dominated by: i) $\mathrm{pH}_{\mathrm{pzc}}$ of selected carbon (Table 2), and ii) the species distribution of pollutants as a function of solution $\mathrm{pH}$ (Table 1). Further, both carbons RSZ and RSP have positive charge density at solution $\mathrm{pH}<\mathrm{pH}_{\mathrm{pzc}}$ and negative charge density at $\mathrm{pH}>\mathrm{pH}_{\mathrm{pzc}}$. Deprotonation is performed on corresponding pollutant at DPA $(\mathrm{pH})>4.66,2,4-\mathrm{D}(\mathrm{pH})>2.98$ and MCPA $(\mathrm{pH})>3.14$. These molecules, consequently, show a negative charge at $\mathrm{pH}$ higher than their $\mathrm{pH}_{\mathrm{PZC}}$.

\section{Influence of ionic strength}

The influence of ionic strength on the adsorption of DPA, 2,4-D and MCPA on carbons RSZ and RSP at

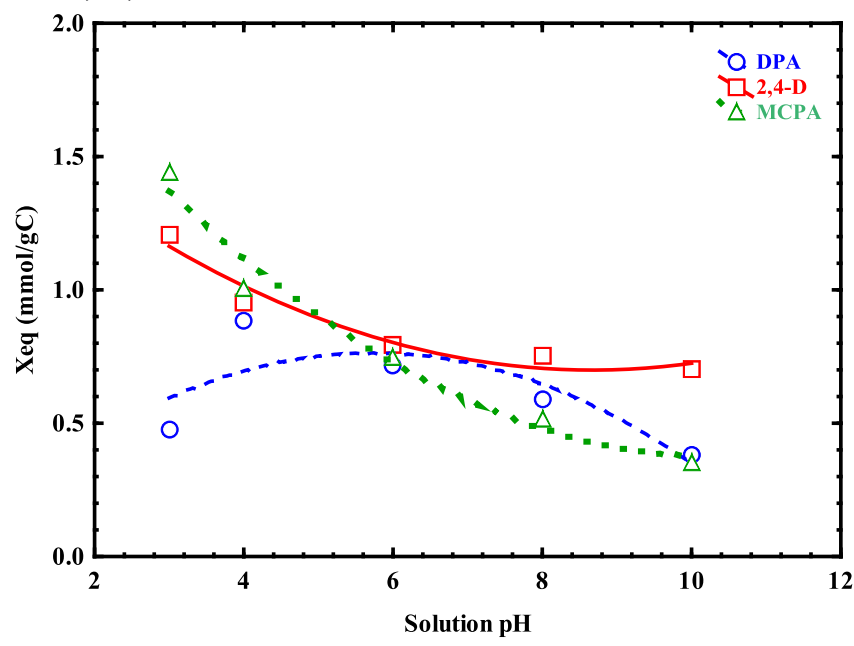

a)

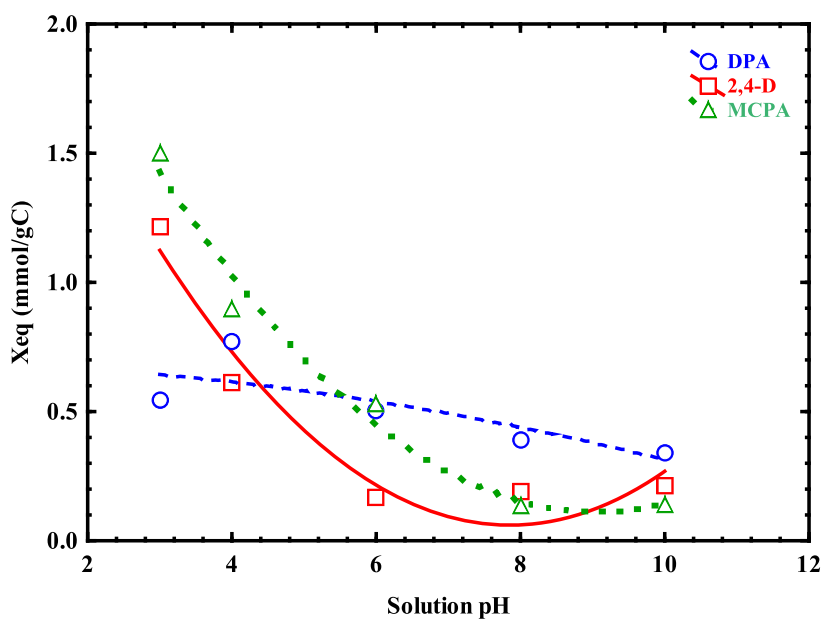

b)

Figure 4. DPA, 2,4-D and MCPA adsorption capacity of activated carbon a) RSZ and b) RSP as a function of solution $\mathrm{pH}, \mathrm{T}=298 \mathrm{~K}$ and $\mathrm{C}_{0}=500 \mathrm{mg} / \mathrm{L}$ 
a solution $\mathrm{pH}$ around 3.20 (without addition of any reagents) is shown in Figs. 5a) and b), respectively. The ionic strength of the solution has minimal influence on the adsorption of all pollutants. Screening effect is mainly the cause of the miniscule reduction in MCPA adsorption observed in the solution containing $\mathrm{NaCl}^{44}$ between the positive and trivial negative charge for RSZ and RSP, respectively. The DPA molecules were protonated at the working $\mathrm{pH}$. Consequently, the presence of ions from NaCL supports adsorbent-adsorbate dispersion interactions due to a screening effect, by that

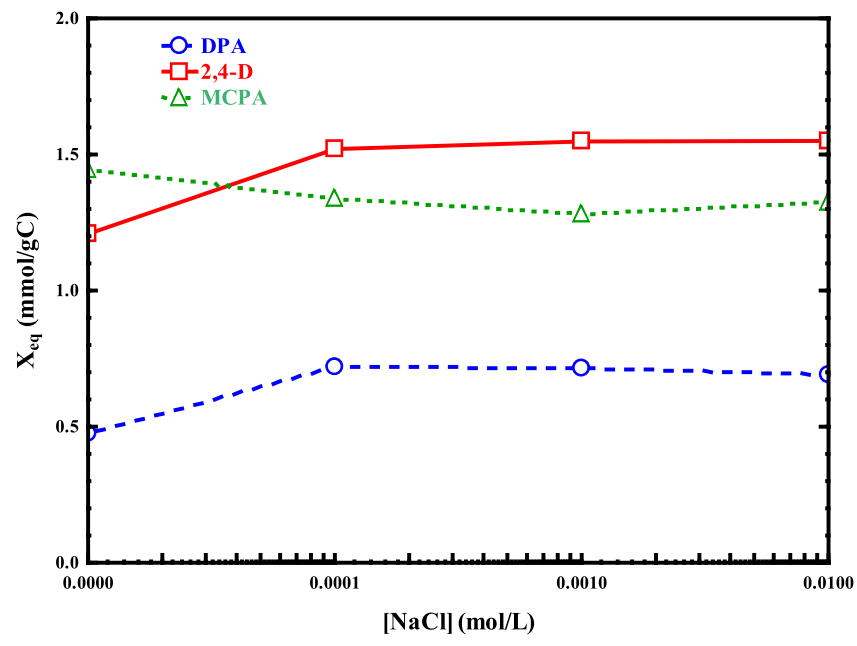

a)

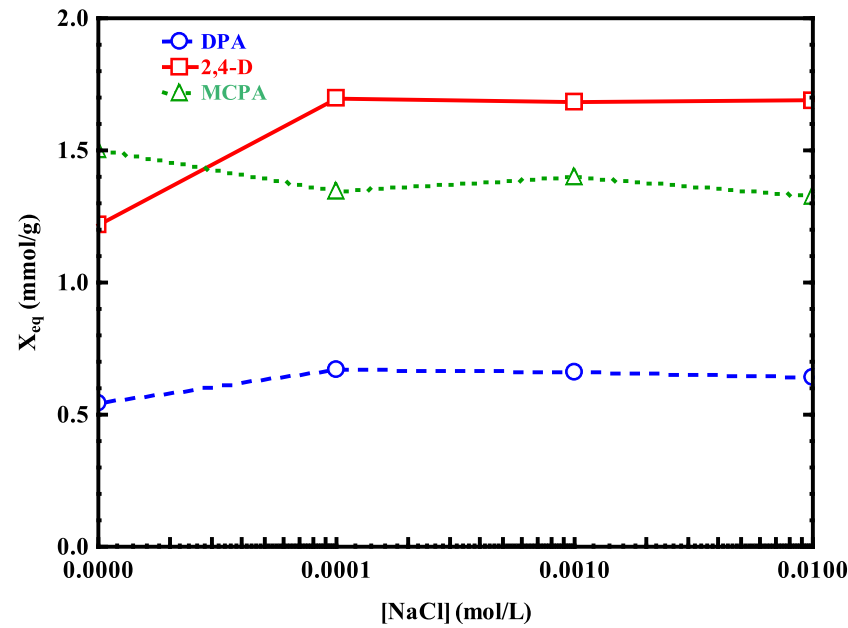

b)

Figure 5. DPA, 2,4-D and MCPA adsorption capacity of activated carbons a) RSZ and b) RSP as a function of ionic strength, $\mathrm{T}=298 \mathrm{~K}, \mathrm{pH}=3.20$ and $\mathrm{C}_{0}=500$ $\mathrm{mg} / \mathrm{L}$ means improving the adsorption of DPA. Furthermore, a slight increase of the adsorption yield for 2,4-D in the presence of $\mathrm{NaCL}$ is attributed to the presence of $\mathrm{NaCL}$ in the solution. This caused a salting-out effect diminishing the solubility of $2,4-\mathrm{D}$, but improving its adsorption onto the carbon surface ${ }^{45}$.

\section{Adsorption process in dynamic regime}

Adsorption of selected pollutants on columns of carbons RSZ and RSP were examined according to Rivera-Utrilla et al. ${ }^{31}$. Table 7 and Fig. 6 showed the result that the adsorbed quantity of pollutants at the breakthrough point $\left(\mathrm{X}_{0.02}\right)$ and the volume of water treated at the

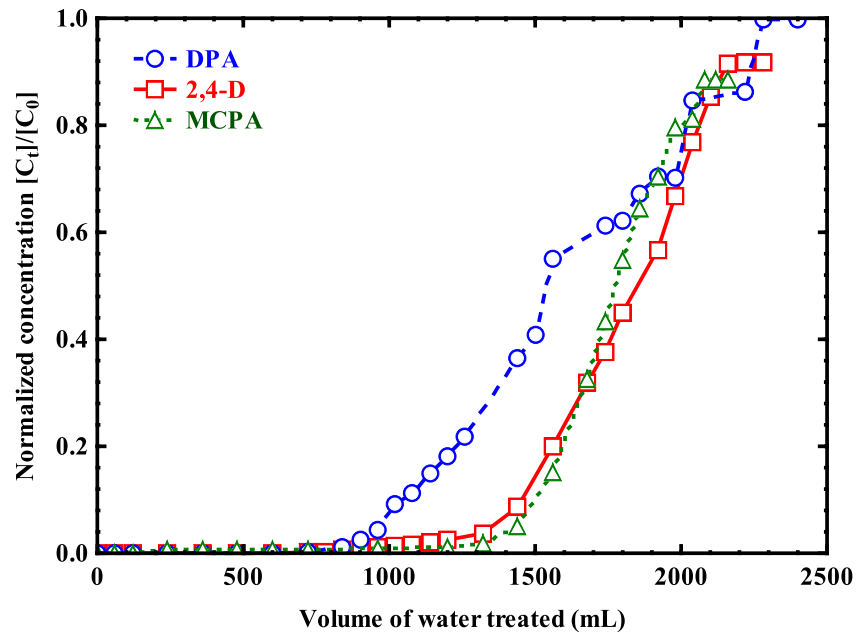

a)

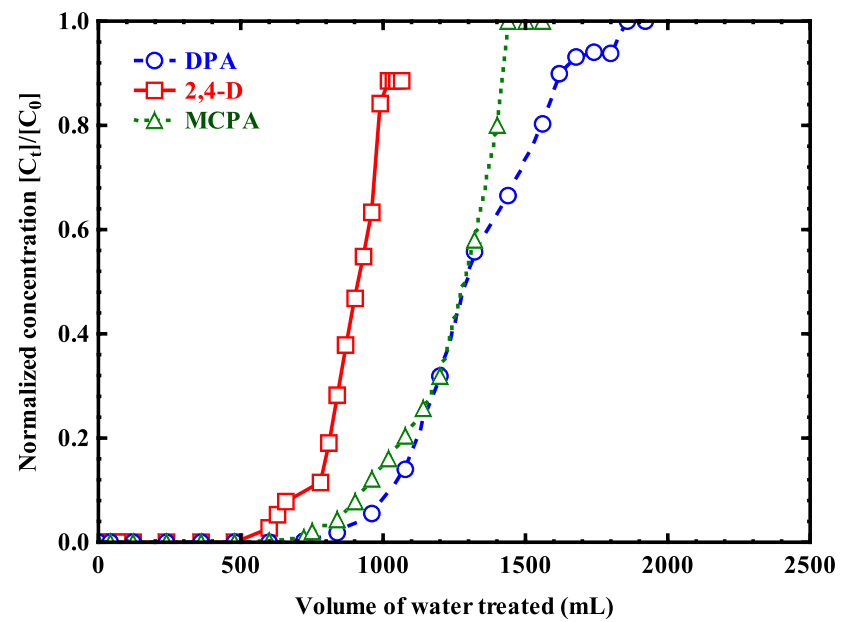

b)

Figure 6. Breakthrough curves for DPA, 2,4-D and MCPA adsorption on activated carbons a) RSZ and b) RSP, $\mathrm{T}=298 \mathrm{~K}, \mathrm{pH}=3.20$ and $\mathrm{C}_{0}=200 \mathrm{mg} / \mathrm{L}$

Table 7. Adsorption parameters obtained by the activated carbon columns

\begin{tabular}{|c|c|c|c|c|c|c|c|}
\hline Pollutant & Carbons & $\begin{array}{c}X_{0.02}{ }^{a)} \\
{[\mathrm{mmol} / \mathrm{g}]}\end{array}$ & $\begin{array}{l}V_{0.02}^{b)} \\
{[\mathrm{mL}]}\end{array}$ & $\Phi^{c)}$ & $\begin{array}{c}\mathrm{H}_{\mathrm{MTZ}}{ }^{\mathrm{d})} \\
{[\mathrm{cm}]}\end{array}$ & $\begin{array}{c}R_{\mathrm{MTZ}} \times 10^{2} \text { e) } \\
{[\mathrm{cm} / \mathrm{min}]}\end{array}$ & $\mathrm{Du}^{\mathrm{f})}[\%]$ \\
\hline \multirow{2}{*}{ DPA } & RSZ & 0.26 & 900 & 0.58 & 2.13 & 0.30 & 64.55 \\
\hline & RSP & 0.10 & 336 & 0.57 & 1.52 & 0.95 & 75.71 \\
\hline \multirow{2}{*}{ 2,4-D } & RSZ & 0.43 & 1140 & 0.71 & 1.26 & 0.53 & 71.90 \\
\hline & RSP & 0.23 & 600 & 0.80 & 1.32 & 0.51 & 69.41 \\
\hline \multirow{2}{*}{ MCPA } & RSZ & 0.52 & 1320 & 0.60 & 1.16 & 0.26 & 80.59 \\
\hline & RSP & 0.30 & 750 & 0.63 & 1.54 & 0.41 & 75.57 \\
\hline
\end{tabular}

a) $\mathrm{X}_{0.02}$ : Amount of pollutant adsorbed at the breakthrough point of the column

b) $\mathrm{V}_{0.02}$ : Volume treated at the breakthrough point of the column

c) $\Phi$ : Fractional capacity of the mass transference zone

d) $\mathrm{H}_{\mathrm{MTZ}}$ : Height of the mass transference zone

e) $R_{M T Z}$ : Rate of movement of the mass transfer zone

f) Du: Degree of utility 
breakthrough point $\left(\mathrm{V}_{0.02}\right)$ for all pollutants was lower for carbon RSP than that for carbon RSZ. These coincide with the results from the static regime - higher adsorption capacity for carbon RSZ than for carbon RSP. Moreover, the amount of pollutants adsorbed in static regime was much higher than that obtained in dynamic regime which is a natural consequence of a shorter contact period between carbon and pollutant and high flow rate $^{\mathbf{3 0}}$. The mass transfer zone is extremely dependent on: a) the nature of the adsorbent-adsorbate interactions, b) carbon bed depth, c) inlet pollutant concentration and d) flow rate. The height of mass transfer zone was higher for carbon RSP bed than that for carbon RSZ bed for all pollutants except DPA. This confirmed that the carbon RSZ is more effective for the treatment of polluted water with 2,4-D and MCPA pollutants. Note, however, that DPA was adsorbed rapidly by RSP reflecting its degree of utility shown in Table 7. It is, therefore, safe to conclude that carbon RSZ should be used as column bed for the effective removal of 2,4-D and MCPA from aqueous solution while carbon RSP is more effective for the treatment of water with DPA pollutants.

\section{CONCLUSION}

Prepared activated carbons RSZ and RSP from rice straw showed high adsorption capacity for removal of DPA, 2,4-D and MCPA regardless of their chemical and textural characters.

The PVDM model fits satisfactorily to the experiment data of a single adsorption of selected pollutants on prepared activated carbons. The range of 1.81 to 6.04 tortuosity factor of the activated carbons was used. Out of the overall intraparticle diffusion, more than $99 \%$ is from pore volume diffusion. Except those cases of DPA on RSP and MCPA on RSZ - $42 \%$ and $85 \%$, respectively. This confirms that the pore volume diffusion controlling mechanism of the overall rate and surface diffusion is negligible.

The adsorption capacity is significantly affected by the solution $\mathrm{pH}$ where the highest capacity of both carbons was observed in an acidic solution. On the contrary, the presence of $\mathrm{NaCl}$ in the solution did not have a significant effect on the activated carbon's adsorption capacity. The amount of pollutants removed by the activated carbons greatly decreased in dynamic regime. This is mainly due to the short contact period between carbon surface and pollutants. Activated carbon RSZ should be used as column bed for effective removal of 2,4-D and MCPA from aqueous solution while carbon RSP proved more effective for treatment of water polluted with DPA. The adsorption mechanism of DPA, 2,4-D, and MCPA onto carbons RSZ and RSP is controlled by dispersion interaction $\pi-\pi$ electrons and electrostatic interaction. Moreover, the contribution of pore volume diffusion, from the overall rate of adsorption, is the controlling mechanism.

\section{ACKNOWLEDGMENT}

The authors are grateful for the financial support provided by PAROWM Scholarships from Egyptian government, MEC-DGI and FEDER (CTQ2011-29035-C02-02), and the Junta de Andalucía (RNM7522) from Spanish government.

\section{ABBREVIATIONS}

a - Prausnitz-Radke isotherm constant, L/g;

b - Prausnitz-Radke isotherm constant, $\mathrm{L}^{\beta} / \mathrm{mmol}^{\beta}$;

$\mathrm{B}$ - Constant related to adsorption energy;

$\mathrm{C}_{\mathrm{A}}$ - The concentration of adsorbate in aqueous solution, $\mathrm{mg} / \mathrm{L}$;

$\mathrm{C}_{\mathrm{A} 0}$ - Initial concentration of adsorbate in aqueous solution, $\mathrm{mg} / \mathrm{L}$;

$\mathrm{C}_{\mathrm{Ar}}$ - The concentration of adsorbate within the particle at distance $\mathrm{r}, \mathrm{mg} / \mathrm{L}$;

$\mathrm{C}_{\mathrm{Ar}} \mathrm{I}_{\mathrm{r}=\mathrm{R}}$ - The concentration of adsorbate at the external surface of the particle at $\mathrm{r}=\mathrm{R}_{\mathrm{p}}, \mathrm{mg} / \mathrm{L}$;

$\mathrm{C}_{\mathrm{Ae}}-$ Concentration of adsorbate at equilibrium, $\mathrm{mg} / \mathrm{L}$;

$\mathrm{D}_{\mathrm{AB}}-$ Molecular diffusion coefficient at infinite dilution, $\mathrm{cm}^{2} / \mathrm{s}$;

$\mathrm{D}_{\text {ep }}$ - Effective pore volume diffusion coefficient, $\mathrm{cm}^{2} / \mathrm{s}$;

$\mathrm{D}_{\mathrm{s}}$ - The surface diffusion coefficient, $\mathrm{cm}^{2} / \mathrm{s}$;

$\mathrm{k}_{1}$ - The rate constant of the first-order kinetic model, $1 / \mathrm{h}$;

$\mathrm{k}_{2}$ - The rate constant of the second-order kinetic model, $\mathrm{g} / \mathrm{mg} / \mathrm{h}$;

$\mathrm{K}_{\mathrm{F}}-$ Relative adsorption capacity;

$\mathrm{k}_{\mathrm{L} \text {, exp }}$ - Experimental external mass transfer coefficient in liquid phase, $\mathrm{cm} / \mathrm{s}$;

$\mathrm{m}$ - Mass of adsorbent, g;

$\mathrm{M}_{\mathrm{B}}$ - The molecular weight of water, $\mathrm{g} / \mathrm{mol}$;

$\mathrm{N}$ - Number of samples taken in the same experiment; $\mathrm{N}_{\mathrm{AP}}-$ Mass transport due to pore volume diffusion, $\mathrm{mg} / \mathrm{cm}^{2} / \mathrm{s}$;

$\mathrm{N}_{\mathrm{AS}}$ - Mass transport due to surface diffusion, $\mathrm{mg} / \mathrm{cm}^{2} / \mathrm{s}$; $\mathrm{n}_{\mathrm{F}}-$ An indicator of sorption intensity or surface heterogeneity;

$\mathrm{q}$ - Mass of adsorbate adsorbed, $\mathrm{mg} / \mathrm{g}$ or $\mathrm{mmol} / \mathrm{g}$;

$\mathrm{q}_{\text {exp }}$ - Experimental mass of adsorbate adsorbed, $\mathrm{mg} / \mathrm{g}$ or $\mathrm{mmol} / \mathrm{g}$;

$\mathrm{q}_{\text {pred,1 }}$ - Mass of adsorbate adsorbed predicted from the first-order kinetic model, $\mathrm{mg} / \mathrm{g}$;

$\mathrm{q}_{\text {pred,2 }}$ - Mass of adsorbate adsorbed predicted from the second-order kinetic model, mg/g;

$\mathrm{r}$ - Distance in radial direction of the particle, $\mathrm{cm}$;

$\mathrm{R}_{\mathrm{p}}$ - Radius of the particle, $\mathrm{cm}$;

$\mathrm{S}$ - External surface area per mass of adsorbent, $\mathrm{m}^{2} / \mathrm{g}$;

$\mathrm{T}$ - Temperature, K;

$\mathrm{t}$ - Time, min;

$\mathrm{V}$ - The volume of the solution, $\mathrm{mL}$;

$\mathrm{V}_{\mathrm{A}}$ - Liquid molar volume at the normal boiling point;

$\mathrm{X}_{\mathrm{eq}}-$ Quantity adsorbate adsorbed per unit mass of adsorbent $(\mathrm{mg} / \mathrm{g})$;

$\mathrm{X}_{\mathrm{m}}$ - Adsorption capacity $(\mathrm{mg} / \mathrm{g})$;

$\% \mathrm{D}$ - Percentage of deviation;

$\mathrm{D}_{0}$ - Combined effective diffusivity;

F - Dimensionless ration.

\section{Greek symbols}

B - Prausnitz-Radke isotherm constant;

$\varepsilon_{\mathrm{p}}-$ Void fraction of particles;

$\eta_{\mathrm{b}}-$ The viscosity of water, cp;

$\varrho_{p}-$ The density of adsorbent particles, $g / m L$;

$\tau$ - Tortuosity factor;

$\phi$ - Association parameter of water; 
$\phi_{\mathrm{A}}-$ The dimensionless concentration of adsorbate in the solution;

$\phi_{\text {exp }}-$ The experimental dimensionless concentration of adsorbate in the solution;

$\phi_{\text {pred }}-$ The dimensionless concentration of adsorbate in the solution predicted with the diffusional models;

$\zeta$ - Dimensionless distance;

$\eta_{\mathrm{A}}$ - The dimensionless concentration of adsorbate within the particle at a distance $r / R_{p}$;

$\theta$ - Dimensionless time $\mathrm{D}_{0} \mathrm{t} / \mathrm{R}_{\mathrm{p}}{ }^{2}$;

$\chi$ - Dimensionless diffusivities $\mathrm{D}_{\mathrm{es}} / \mathrm{D}_{\mathrm{ep}}$;

$\omega-$ Dimensionless ratio $\rho_{\mathrm{p}} \mathrm{q}_{0} / \mathrm{C}_{\mathrm{A} 0}$.

\section{LITERATURE CITED}

1. Serrano, R., Portolés, T., Blanes, M.A., Hernández, F., Navarro, J.C., Varó, I. \& Amat, F. (2012). Characterization of the organic contamination pattern of a hyper-saline ecosystem by rapid screening using gas chromatography coupled to highresolution time-of-flight mass spectrometry, Sci. Total Environ. 433, 161-168. DOI: 10.1016/j.scitotenv.2012.06.042.

2. Moreno-González, R., Campillo, J.A., García, V. \& León, V.M. (2013). Seasonal input of regulated and emerging organic pollutants through surface watercourses to a Mediterranean coastal lagoon. Chemosphere 92, 247-257. DOI: 10.1016/j. chemosphere.2012.12.022.

3. Orton, F., Lutz, I., Kloas, W. \& Routledge, E.J. (2009). Endocrine disrupting effects of herbicides and pentachlorophenol: in vitro and in vivo evidence, Sci. Total Environ. 43(6), 2144-2150. DOI: 10.1021/es8028928.

4. Han, D., Jia, W. \& Liang, H. (2010). Selective removal of 2,4-dichlorophenoxyacetic acid from water by molecularlyimprinted amino-functionalized silica gel sorbent, J. Environ. Sci. 22(2), 237-241. DOI: 10.1016/S1001-0742(09)60099-1.

5. Aksu, Z. \& Kabasakal, E. (2004) Batch adsorption of 2,4-Dichlorophenoxy-acetic acid (2,4-D) from aqueous solution by granular activated carbon, Sep. Purif. Technol. 35, 223-240. DOI: 10.1016/S1383-5866(03)00144-8.

6. Peixoto, F.P., Lopes, M.L., Madeira, V.M.C. \& Vicente, J.A.F. (2009). Toxicity of MCPA on non-green potato tuber calli, Acta Physiol. Plant. 31, 103-109. DOI 10.1007/s11738-008-0207-x.

7. Cerbai, B., Solaro, R. \& Chiellini, E. (2008). Synthesis and characterization of functionalpolyesters tailored for biomedical applications. J. Polym. Sci. A1. 46, 2459-2476. DOI: 10.1002/pola.22579.

8. Zhang, R. \& Moore, J.A. (2003). Synthesis, characterization and properties of polycarbonate containing carboxyl side groups, Macromol. Symp. 199, 375-390. DOI: 10.1002/ masy. 200350932.

9. Gültekin, I. \& Ince, N.H. (2007). Synthetic endocrine disruptors in the environment and water remediation by advanced oxidation processes, J. Environ. Manage 85, 816-832. DOI: 10.1016/j.jenvman.2007.07.020.

10. Laganà, A., Bacaloni, A., De Leva, I., Faberi, A., Fago, G. \& Marino, A. (2004). Analytical methodologies for determining the occurence of endocrine disrupting chemicals in sewage treatment plants and natural waters, Anal. Chim. Acta 501, 79-88. DOI: 10.1016/j.aca.2003.09.020.

11. Mailler, R., Gasperi, J., Coquet, Y., Derome, C., Buleté, A., Vulliet, E., Bressy, A., Varrault, G., Chebbo, G. \& Rocher, V. (2016). Removal of emerging micropollutants from wastewater by activated carbon adsorption: Experimental study of different activated carbons and factors influencing the adsorption of micropollutants in wastewater, J. Environ. Chem. Eng. 4, 1102-1109. DOI: 10.1016/j.jece.2016.01.018.

12. Ocampo-Pérez, R., Abdel daiem, M.M., Rivera-Utrilla, J., Méndez-Díaz, J.D. \& Sánchez-Polo M. (2012). Modeling adsorption rate of organic micropollutants present in landfill leachates onto granular activated carbon, J. Colloid Interf. Sci. 385, 174-182. DOI: 10.1016/j.jcis.2012.07.004.

13. Abdel daiem, M.M., Rivera-Utrilla, J., Ocampo-Pérez, R., Sánchez-Polo, M. \& López-Peñalver, J.J. (2013). Treatment of water contaminated with diphenolic acid by gamma radiation in the presence of different compounds, Chem. Eng. J. 219, 371-379. DOI: 10.1016/j.cej.2012.12.069.

14. Rivera-Utrilla, J., Sánchez-Polo, M., Abdel daiem, M.M. \& Ocampo-Pérez, R. (2012). Role of activated carbon in the photocatalytic degradation of 2, 4-dichlorophenoxyacetic acid by the $\mathrm{UV} / \mathrm{TiO}_{2} /$ activated carbon system, Appl. Catalysis-B: Environ. 126, 100-107. DOI: 10.1016/j.apcatb.2012.07.015.

15. Tchaikovskaya, O.N., Karetnikova, E.A., Sokolova, I.V., Mayer, G.V. \& Shvornev, D.A. (2012). The phototransformation of 4-chloro-2-methylphenoxyacetic acid under $\mathrm{KrCl}$ and $\mathrm{XeBr}$ excilamps irradiation in water. J. Photoch. Photobio. A 228, 8-14. DOI: 10.1016/j.jphotochem.2011.11.004.

16. Rivera-Utrilla, J., Sánchez-Polo, M., Gómez-Serrano, V., Álvarez, P.M., Alvim-Ferraz, M.C.M. \& Dias, J.M. (2011). Activated carbon modifications to enhance its water treatment applications. An overview. J. Hazard. Mater. 187, 1-23. DOI: 10.1016/j.jhazmat.2011.01.033.

17. Daifullah, A.A.M., Yakout, S.M. \& Elreefy, S.A. (2007). Adsorption of fluoride in aqueous solutions using $\mathrm{KMnO}_{4^{-}}$ modified activated carbon derived from steam pyrolysis of rice straw, J. Hazard. Mater. 147, 633-643. DOI: 10.1016/j. jhazmat.2007.01.062.

18. Dias, J.M., Alvim-Ferraz, M.C.M., Almeida, M.F., RiveraUtrilla, J. \& Sánchez-Polo, M. (2007). Waste materials for activated carbon preparation and its use in aqueous-phase treatment: a review. J. Environ. Manage. 85 (2007) 833-846

19. Hameed, B.H., Salman, J.M. \& Ahmad, A.L. (2009). Adsorption isotherm and kinetic modeling of 2,4-D pesticide on activated carbon derived from date stones, J. Hazard. Mater. 163, 121-126. DOI: 10.1016/j.jhazmat.2008.06.069.

20. Said, N., El-Shatoury, S.A., Díaz, L.F. \& Zamorano, M. (2013). Quantitative appraisal of biomass resources and their energy potential in Egypt, Renew. Sust. Energ. Rev. 24, 84-91. DOI: 10.1016/j.rser.2013.03.014.

21. Ahmedna, M., Marshall, W.E. \& Rao, R.M. (2000). Production of granular activated carbons from select agricultural by-products and evaluation of their physical, chemical and adsorption properties, Bioresour. Technol. 71, 113-123. DOI: 10.1016/S0960-8524(99)00070-X.

22. Said, N., Bishara, T., García-Maraver, A. \& Zamorano, M. (2013). Effect of water washing on the thermal behavior of rice straw, Waste Manage. 33, 2250-256. DOI: 10.1016/j. wasman.2013.07.019.

23. Bautista-Toledo, M.I, Méndez-Díaz, J.D., Sánchez-Polo, M., Rivera-Utrilla, J. \& Ferro-García, M.A. (2008). Adsorption of sodium dodecylbenzenesulfonate on activated carbons: Effects of solution chemistry and presence of bacteria, J. Colloid Interf. Sci. 317, 11-17. DOI: 10.1016/j.jcis.2007.09.039.

24. Rivera-Utrilla, J. \& Sánchez-Polo, M. (2004). Ozonation of naphthalenesulphonic acid in the aqueous phase in the presence of basic activated carbons, Langmuir 20, 9217-9222. DOI: $10.1021 / 1 \mathrm{a} 048723+$.

25. Rivera-Utrilla, J., Bautista-Toledo, I., Ferro-García, M.A. \& Moreno-Castilla, C. (2003). Bioadsorption of Pb (II), Cd (II), and Cr (VI) on activated carbon from aqueous solutions, Carbon 41, 323-330. DOI: 10.1016/S0008-6223(02)00293-2.

26. Leyva-Ramos, R. \& Geankoplis, C.J. (1985). Model simulation and analysis of surface diffusion of liquid in porous solids, Chem. Eng. Sci. 40(5), 799-807. DOI: 10.1016/00092509(85)85032-6.

27. Leyva-Ramos, R. \& Geankoplis, C.J. (1994). Diffusion in liquid filled pores of activated carbon, I: pore volumen diffusion, Can. J. Chem. Eng. 72(2), 262-271. DOI: 10.1002/ cjce. 5450720213 . 
28. Choong, T.S.Y., Wong, T.N., Chuah, T.G. \& Idris, A. (2006). Film-pore-concentration-dependent surface diffusion model for the adsorption of dye onto palm kernel shell activated carbon. J. Colloid Interf. Sci. 301(2), 436-440. DOI: 10.1016/j.jcis.2006.05.033.

29. Schiesser, W.E. \& Silebi, C.A. (1997). Computational Transport Phenomena. Numerical Methods for the solution of Transport Problems 1995-1997: Cambridge University Press: Cambridge, U.K.

30. Méndez-Díaz, J.D., Abdel daiem, M.M., Rivera-Utrilla, J., Sánchez-Polo, M. \& Bautista-Toledo, I. (2012). Adsorption/ bioadsorption of phthalic acid, an organic micropollutant present in landfill leachates, on activated carbons, J. Colloid Interf. Sci. 369, 358-365. DOI: 10.1016/j.jcis.2011.11.073.

31. Rivera-Utrilla, J., Prados-Joya, G., Sánchez-Polo, M., Ferro-García, M.A. \& Bautista-Toledo, I. (2009). Removal of nitroimidazole antibiotics from aqueous solution by adsorption/bioadsorption on activated carbon, J. Hazard. Mater. 170, 298-305. DOI: 10.1016/j.jhazmat.2009.04.096.

32. De Lange, M.F., Vlugt, T.J.H., Gascon, J. \& Kapteijn, F. (2014). Adsorptive characterization of porous solids: Error analysis guides the way, Micropor Mesopor Mat. 200, 199-215, DOI: 10.1016/j.micromeso.2014.08.048.

33. Kalderis, D., Koutoulakis, D., Paraskeva, P., Diamadopoulos, E., Otal, E., Valle, J.O.D. \& Fernández-Pereira, C. (2008). Adsorption of polluting substances on activated carbons prepared from rice husk and sugarcane bagasse. Chem. Eng. J. 144, 42-50. DOI: 10.1016/j.cej.2008.01.007.

34. Elmouwahidi, A., Zapata-Benabithe, Z., Carrasco-Marín, F. \& Moreno-Castilla, C. (2012). Activated carbons from $\mathrm{KOH}$-activation of argan (Argania spinosa) seed shells as supercapacitor electrodes, Bioresour. Technol. 111, 185-190. DOI: 10.1016/j.biortech.2012.02.010.

35. Giles, C.H., Smith, D. \& Huitson, A. (1974). A General treatment and classification of the solute adsorption isotherm I. Theoretical, J. Colloid Interf. Sci. 47, 755-765. DOI: 10.1016/0021-9797(74)90252-5.

36. Giles, C.H., D’Silva, A.P. \& Easton, I.A. (1974). A general treatment and classification of the solute adsorption isotherm Part II. Experimental Interpretation, J. Colloid Interf. Sci. 47, 766-778. DOI: 0.1016/0021-9797(74)90253-7.

37. Noll, K.E., Gounaris, V. \& Hou, W.S. (1992). Adsorption Technology for Air and Water Pollution Control ( $1^{\text {st }}$ ed.). Michigan, USA: Lewis Publishers

38. Poling, B.E., Prausnitz, J.M. \& O'Connell, J.P. (2001). The Properties of Gases and Liquids ( $5^{\text {th }}$ ed.) New York, USA: McGraw-Hill Companies.

39. Furusawa, Y. \& Smith, J.M. (1973). Fluid-Particle and Intraparticle Mass Transport Rates in Slurries. Ind. Eng. Chem. Fundamen. 12 (2), 197-203. DOI: 10.1021/i160046a009.

40. Ruthven, D.M. (1984). Principles of adsorption and adsorption processes; New Brunswick University: Fredericton, Canada.

41. Do, D.D. (1998). Adsorption analysis: Eguilibria and kinetics; Queensland University Press: Queensland, Australia.

42. Suzuki, M. (1990). Adsorption Engineering; Tokyo University Press: Tokyo, Japan.

43. Leyva-Ramos, R., Rivera-Utrilla, J., Medellín-Castillo, N.A. \& Sánchez-Polo, M. (2009). Kinetic modelling of naphthalenesulphonic acid adsorption from aqueous solution onto untreated and ozonated activated carbons, Adsorpt. Sci. Technol. 27 (4), 395-411. DOI: 10.1260/026361709790252650.

44. López-Ramón, V., Moreno-Castilla, C., Rivera-Utrilla, J. \& Radovic, L.R. (2003). Ionic strength effects in aqueous phase adsorption of metal ions on activated carbons, Carbon 41, 2020-2022. DOI: 0.1016/S0008-6223(03)00184-2.

45. Barton, S.S., Evans, M.J.B. \& MacDonald, J.A.F. (1994). Adsorption of water vapor on nonporous carbon. Langmuir 10, 4250-4252. DOI: 10.1021/la00023a055. 